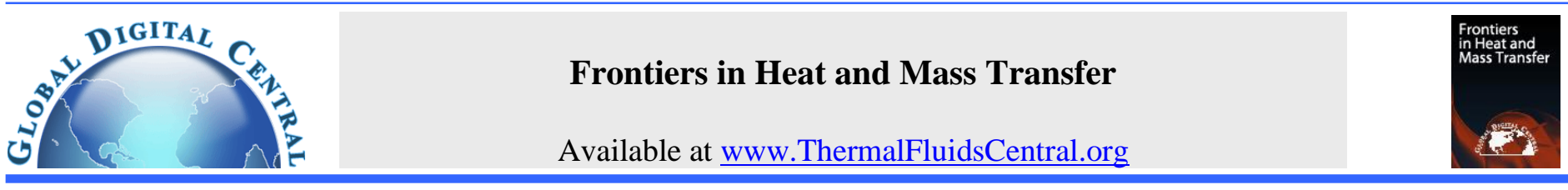

\title{
RECENT ADVANCES OF SURFACE WETTABILITY EFFECT ON FLOW BOILING HEAT TRANSFER PERFORMANCE
}

\author{
Shuang Cao ${ }^{\text {a,* }}$, Hui Yang a , Luxing Zhao a, Tao Wang a , Jian Xie ${ }^{b, \dagger}$ \\ ${ }^{a}$ School of Energy and Power Engineering, Zhengzhou University of Light Industry, Zhengzhou 450002, China \\ ${ }^{b}$ Beijing Key Laboratory of Multiphase Flow and Heat Transfer for Low Grade Energy Utilization, North China Electric Power University, Beijing \\ 102206, China
}

\begin{abstract}
Flow boiling heat transfer is an effective way to fulfill the energy transfer. The wettability of boiling surface influences the liquid spreading ability and the growth, departure, and release frequency of bubbles, which determines the heat transfer performance. According to the wettability and combination forms, boiling surface are classified into weak wetting surface, strong wetting surface, and heterogeneous wetting surface. Fabricating by physical, chemical method or coating the original surface with a layer of low surface energy, the weak wetting surface has more effective activation point and nucleation center density to improve heat transfer performance at low heat flux. The strong wetting surface always formed by physical or chemical treatment to enhance the rapid rewetting of the wall surface. It has a smaller bubble separation diameter, higher separation frequency and higher CHF. The heterogeneous wetting surface, having the synthetic effects of the strong and weak surface wettabilities, is a hot issue of recent study. But its composition and heat transfer enhancement mechanism are very complicated which need to study thoroughly. Furthermore, the intelligent wetting surface, having the dynamics wettability function, is also briefly analyzed in this paper. Despite the advances in this aspect, the boiling surfaces can be further optimized by fabricate effective wettability to achieve a strong stability, high heat transfer performance and realize the synergistic effect of flow pattern and heat transfer.
\end{abstract}

Keywords: flow boiling; wettability; heat transfer enhancement; heterogeneous surface; intelligent wetting surface

\section{INTRODUCTION}

As an efficient mode of heat transfer with high heat flux, flow boiling is a phase change process in which vapor bubbles are formed when liquid flow over a heated surface or inside a heated tube. The heat transfer equipment with flow boiling heat transfer has been widely used in chemical energy, power cycle, refrigeration, electronics and other industries (Suhas et al. 2019; Lian et al. 2020; Hong et al. 2020; Zhang et al. 2020; Abo-Zahhad et al. 2021). Enhancing flow boiling heat transfer could significantly reduce the size and investment cost of such industry applications.

Actually, boiling is a solid-liquid-vapor interaction phenomenon which heats liquid working fluid to vapor on the solid heated surface. Surface wettability refers to the spreading ability of liquid on the solid surface and it plays a very important role to affect the boiling heat transfer performance (Mohammadi et al. 2018; Shi et al. 2020; Fan et al. 2020; Ferjančič et al. 2020; Guo et al. 2020). Generally, the static contact angle $\theta$ is the important parameters to characterize the degree of wettability of a solid surface. According to Wenzel (1936) equation (Eq. 1 ), the wettability of surface is dominated by the physical structure and modification treatments. The surface physical structure is related to the surface roughness. The intrinsic wettability of the surface increased with increasing surface roughness. On the other hand, the surface modification treatments could improve wettability to heighten the free energy of solid surface.

*Corresponding author. Email: caos@zzuli.edu.cn

${ }_{\dagger}$ Corresponding author. Email: xiejian90@ncepu.edu.cn

$$
\cos \theta=r\left(\gamma_{\mathrm{sg}}-\gamma_{\mathrm{sl}}\right) / \gamma_{\mathrm{lg}}
$$

Where $\theta$ is the apparent contact angle between liquid and solid, $r$ is the ratio of the real area of rough surface to apparent area, and $\gamma$ is the surface tension force, respectively. The subscripts $g, l$ and $s$ refer to gas, liquid and solid, respectively.

In this paper, the effect of surface wettability on flow boiling is reviewed. Depending on the wettability and combination forms, the boiling surfaces is divided into weak wetting surface, strong wetting surface and heterogeneous wetting surface. The weak wetting surface has the limited contact angle ranges of $90^{\circ}-180^{\circ}$, including the hydrophobic surface $\left(90^{\circ}<\theta<150^{\circ}\right)$ and superhydrophobic surface $\left(\theta>150^{\circ}\right)$. However, the strong wetting surface, the contact angle is less than $90^{\circ}$, including the hydrophilic surface $\left(10^{\circ}<\theta<90^{\circ}\right)$ and superhydrophilic surface $\left(\theta<10^{\circ}\right)$. The heterogeneous wetting surface refers to the mixed surface composed of strongly wetting region and weak wetting region. The effects of these three kinds of wettability surfaces on the vapor bubble dynamics together with the boiling heat transfer performance are introduced. Further, the preparation methods of different wettability surfaces are reviewed. Then, the intelligent wettability surfaces with adaptive functions are briefly analyzed. Finally, the prospect of enhancing flow boiling heat transfer performance on wettability surfaces is presented. 


\section{EFFECT OF SURFACE WETTABILITY ON BUBBLE DYNAMICS AND HEAT TRANSFER}

It should be emphasized that the nucleation, growth, departure, and release frequency of bubbles is the basement and form of flow boiling process. The surface wettability has a significant effect on the bubble periods to dictate flow pattern transformation. The flow boiling heat transfer performance is mainly subjected to bubbles dynamics and flow pattern. Thus, the bubble dynamics can be controlled to enhance flow boiling heat transfer by modulating surface wettability. Therefore, it is necessary to study the effect of surface wettability on bubble dynamic and heat transfer enhancement mechanism.

\subsection{Bubble Dynamics on the Homogeneous Wetting Surface}

The bubble dynamics on the homogeneous wetting surfaces (strong and weak wetting surface) are different as shown in Fig. 1 (Jo et al. 2011). For the strong wetting surface, the bubbles gradually grow to a certain critical size until they were departure from the boiling surface. But for weak wetting surface, bubbles nucleate on the surface and grow along with time. Then, part of the bubbles will leave the boiling surface when they grow to a certain extent, while the others remain on the surface as the nucleation point of the next bubbles without any waiting time, which is the necking phenomenon. The necking phenomenon has also confirmed by numerical simulation (Nam et al. 2009). In addition, Abarajith and Dhir (2002) investigated the effect of wettability $\left(1^{\circ}<\theta<90^{\circ}\right)$ on bubble life period. The results showed that the bubble growth period increased with the increasing contact angle. Nam et al. (2011) explored the life period of single bubble on a strong wetting surface with the combination research method of experiment and numerical simulation. They found that the bubble period on superhydrophilic surface behaves 4 times shorter than that on hydrophilic surface.

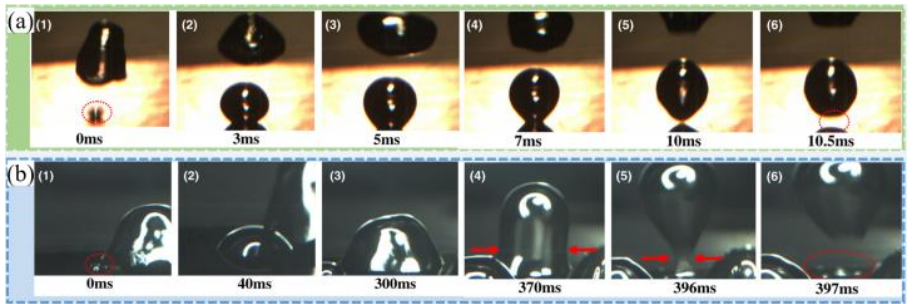

Fig. 1 The bubble dynamics on (a) hydrophilic surfaces and (b) hydrophobic surface (Jo et al. 2011).

Bubble nucleation is the starting point of boiling and has been studied for years (Carey 1992; Mer 1952; Liu et al. 2005). Quan et al. (2011) established a thermodynamic model based on Gibbs free energy and the availability criterion for onset of heterogeneous nucleation on heated surfaces with different wettability. They indicated that a more hydrophobic surface easily occur bubble nucleation. Dong et al. (2012) performed an analysis of the Gibs function criterion $(\Delta G=0)$ and the availability criterion $(\mathrm{d} \Delta \psi / \mathrm{d} r=0)$ for heterogeneous bubble nucleation. They concluded that hydrophobic surfaces are more likely to bubble nucleate.

Some visualization experiments also confirmed that bubbles were generated on hydrophobic surfaces first (Forrest et al. 2010), but only macroscopically observing the occurrence sequence of bubbles on different wettability surfaces could not explain the mechanism of bubble nucleation in a deeper way. However, some simulation method can analyze the effects of different wettability surfaces on bubble nucleation at a micro scale. Lavino et al. (2021) showed bubble nucleation can occur even in narrow cavities on hydrophobic surface by non-equilibrium molecular dynamics simulation method. This also confirms the previous conclusion that bubble nucleation is more likely to occur on hydrophobic surfaces. In addition, Chen et al. (2020) investigated the bubble nucleation on grooved substrates with different wettability by molecular dynamics simulation method. They found a visible bubble nucleus generated on the hydrophilic groove surface from nothing, and the bubble nucleation rate increased with increase of groove hydrophilicity. Furthermore, bubble nucleation on different wetting surfaces was explained by the competition between atomic potential energy and atomic kinetic energy. Zhang et al. (2020) used lattice Boltzmann method to investigate the nucleation site interactions during boiling. Different from the hydrophilic surface, the nucleation site interaction on the hydrophobic surface is mainly promoting. Recently, Tang et al. (2021) found the surface phase transition is driven by surface-catalysed heterogeneous nucleation. Hence, bubble nucleation is a heterogeneous nucleation process at the solid-liquid interface.

In this paper, bubble growth refers to the motion characteristics of bubbles from nucleation to departure. Different wettability surfaces have different effects on bubble growth. As shown in Fig. 2 (a), Zupančič et al. (2015) reported the hydrophilic surface has an average maximum bubble contact diameter of $4 \mathrm{~mm}$ and a nucleation-site density approximately of 4 sites/cm, respectively. However, the average maximum bubble contact diameter and nucleation-site density approximately of superhydrophilic surface are $1.3 \mathrm{~mm}$ and 16 sites $/ \mathrm{cm}$, respectively. Li et al. (2021) found the average bubble diameter on the superhydrophobic surface is the largest. The bubbles on the hydrophilic surface are more sparse and smaller (see Fig. 2b).
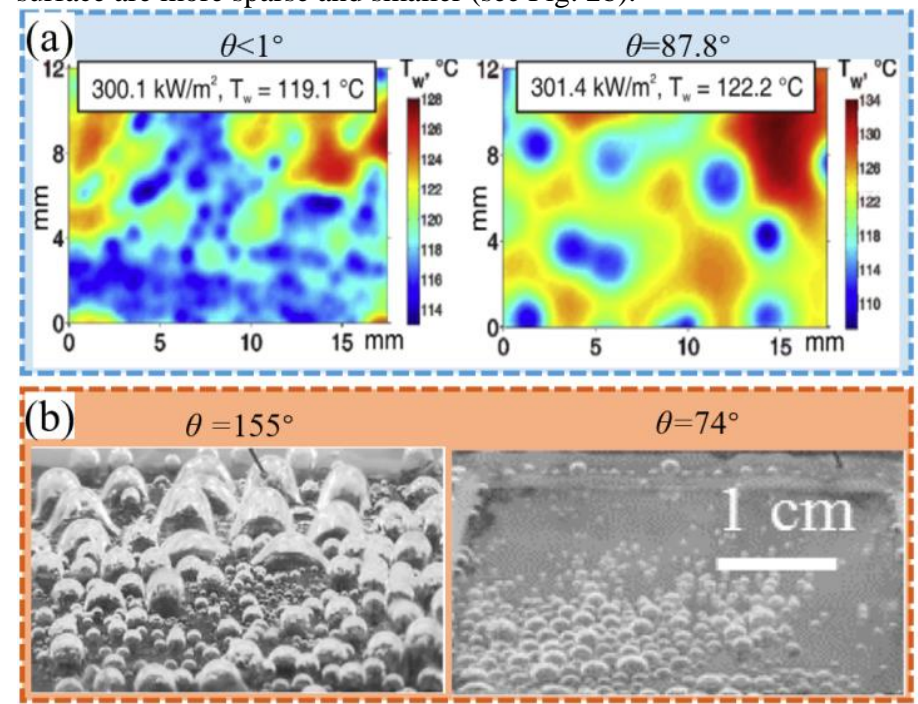

Fig. 2 (a) Temperature fields on the superhydrophilic (left) and hydrophilic surface (right) (Zupančič et al. 2015), (b) Visualization of boiling on superhydrophobic (left) and hydrophilic surface (right) (Li et al. 2021).

In addition, Kim et al. (2019) explored the effects of wettability on the bubble grow of microchannels by numerically. They found the bubble of hydrophilic channel is spherical and the interface is stable. However, the bubble of hydrophobic channel is elliptical and the interface is unstable. The density of active nucleation points in hydrophobic channels is higher than that on hydrophilic surface, especially at low mass flux. Zhao et al. (2021) also found the spherical bubble occurs on the hydrophilic surface and the bubble growth rate is faster. Allred et al. (2021) explored the effects of dynamics contact angles on bubble growth and bubble departure morphologies. The lower dynamic contact angle yields the smaller contact and departure diameters.

As an important process in the bubble growth, bubbles coalescence has also attracted the attention of researchers. Sadaghiani et al. (2019) reported that vertical bubble coalescence mainly occurred on the hydrophilic surfaces and horizontal bubble coalescence mainly occurred on the hydrophobic surface. Recently, Yuan et al. (2021) used lattice Boltzmann method to simulate the coalescence behavior of double bubbles on different wetting surfaces. When bubbles gather on the hydrophilic surface, they can capture the liquid microlayer, while bubbles on the hydrophobic surface are more likely to coalescence on the 
wall surface to form a vapor layer. There is a critical coalescence distance for the coalescence of double bubbles (when the distance is greater than this distance, the bubbles do not coalesce), which depends on the distance between the bubble diameter and the nucleation point. The critical coalescence distance increases with the increase of the contact angle.

The bubble departure characteristics (departure diameter and departure frequency) are the important parameters in the bubble boiling period. The surface wettability has an important effect on the bubble departure characteristics. According to the classical boiling theory (Fritz 1935; Zuber 1963), the mathematical expression between the contact angle of solid-liquid interface and the bubble departure diameter is:

$$
\begin{aligned}
& d=0.0208 \theta \sqrt{\frac{\gamma_{\mathrm{lg}}}{g\left(\rho_{1}-\rho_{\mathrm{g}}\right)}} \\
& f d=C\left[\frac{\gamma_{\mathrm{lg}} g\left(\rho_{1}-\rho_{\mathrm{g}}\right)}{\rho_{1}^{2}}\right]^{1 / 4}
\end{aligned}
$$

Where $f$ is the bubbles departure frequency, $d$ is bubbles departure diameter, $\rho$ is the density of working fluid, $C$ is an independent parameter which value depends on the property of liquid working fluid (for water, $C$ is 0.59 ), respectively.

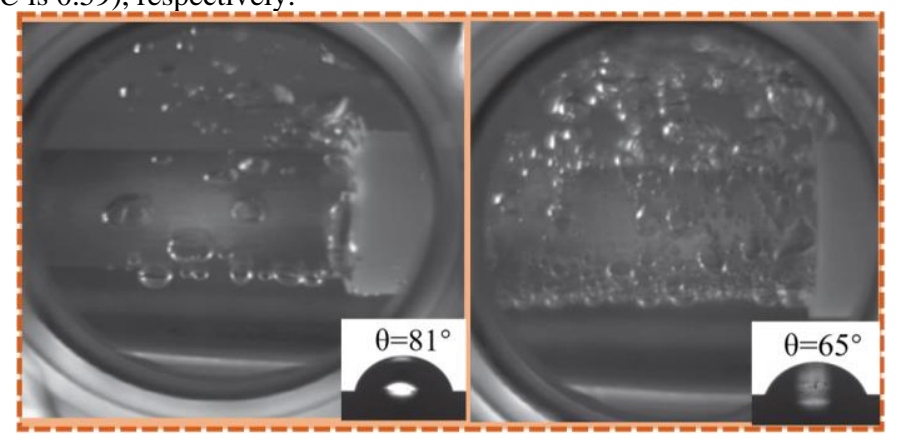

Fig. 3 Visualization of bubble separation diameter and frequency on the on hydrophilic surface (left) and more hydrophilic surface (right) (Yim et al. 2019).

It can be seen that, as the decreasing contact angle, the bubble separation frequency is increased, whereas the bubble separation diameter is decreased. This phenomenon has been demonstrated by a great deal of visualization experiments (Ruiz et al. 2017; Yim et al. 2019), which can be seen in Fig. 3. Bubble departure diameters were found almost 2.5 times smaller on the superhydrophilic surface (Nam et al. 2011) and 3 times larger on the hydrophobic surface (Nam et al. 2009) compared to the hydrophilic surface. In addition, Sarker et al. (2019) indicated the single bubble departure diameter decreased from $1.75 \mathrm{~mm}$ to $0.75 \mathrm{~mm}$ with the decrease of contact angle decrease from $65.30^{\circ}$ to $42.32^{\circ}$. Moreover, Nie et al. (2021) studied the effect of surface wettability on bubble separation in flow boiling by the two-phase lattice Boltzmann method. They found the fluid flow has little effect on the release period of the bubble on the hydrophilic surface. However due to the necking phenomenon, the fluid flow promotes the bubble to leave the hydrophobic surface.

\subsection{Bubble Dynamics on the Heterogeneous Wetting Surface}

For the heterogeneous wetting surface, the four stages (nucleation, growth, coalescence, departure) of bubble dynamics are different from homogeneous wetting surface. Li et al. (2020) analyzed the bubble nucleation on different wettability surfaces by molecular dynamics simulations. They found that the weak wetting surface has small binding force on liquid atoms. Compared with the uniformly wetting surface, the heterogeneous wetting surface combines the advantages of the strong wetting surface and the weak wetting surface, which promotes the nucleation of bubbles on the nanometer scale.

Jo et al. (2016) reported the critical size for slip behavior to design a heterogeneous wetting surface by observing bubble dynamics on the hydrophobic-hydrophilic composite surface. The bubbles will form and grow to the edge of the hydrophobic dots and the triple line will be pinned on the boundary of the hydrophobic dots when the size of the hydrophobic dots smaller than the critical size for slip behavior. However, the bubble may combine with the adjacent bubble to form a vapor film to deteriorate the boiling heat transfer when the size of the hydrophobic dots larger than the critical size for slip behavior. Pontes et al. (2020) concluded that the small superhydrophobic area on the hydrophilic surface can promote the formation of regular and stable bubbles. Li et al. (2021) observed the bubbles growth on two hydrophilic/hydrophobic area ratio on heterogeneous wetting surfaces (see Fig. 4). The bubbles on the heterogeneous surface are more orderly. The sideslip and merging of bubbles occur on the small area ratio surface. The bubble sizes are more average on the surface with large area ratio.

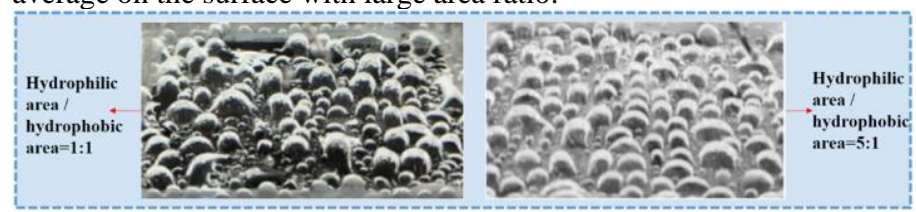

Fig. 4 Visualization of boiling on heterogeneous surface (Li et al. 2021).

In addition, Wang et al. (2019) investigated the bubble dynamics in a microchannel with a heterogeneous wetting surface. They found the nucleation easily occurs on the hydrophobic dots and the bubbles show higher mobility and longer triple contact lines on the heterogeneous surface. The bubble will "jump" from the hydrophilic region to hydrophobic dots when they reach the hydrophilic and hydrophobic boundary. Kim et al. (2020) performed a numerical investigation on bubble dynamics of three heterogeneous wetting surfaces, namely crosswise, parallel and dotted patterns, for flow boiling in a microchannel. The phenomenon of "jumping" also exists on the crosswise and dotted patterns surface. For parallel pattern surface, the bubbles are confined in the hydrophobic patterns and contact line pinning in the transverse direction yields elongation of bubbles along the direction of flow. Recently, Zhao et al. (2021) demonstrated that the bubble appear first in the hydrophobic region of the heterogeneous wetted surface at the atomic scale.

Pontes et al. (2020) recommended that heterogeneous wetting surfaces should have small superhydrophobic areas and the distance between the superhydrophobic areas is suggested to be on the order of one bubble diameter to prevent bubble coalescence. Cheng et al. (2021) observed the bubble dynamics on the hydrophilic substrate with different wettability patterns (the contact angle are $10^{\circ}, 90^{\circ}, 120^{\circ}, 150^{\circ}$ ). They found the larger bubble departure diameter tend to occur on the boiling surfaces with higher contact angle values. The waiting time decreased with an increase in contact angle.

For the heterogeneous wetting surface, the bubble dynamic is complex due to the combination type, shape and parameters (size, pitch and area fraction). Thus, a lot of experimental researches and numerical simulations of which are carried out (Jo et al. 2014; Wi et al. 2018; Li et al. 2018; Yu et al. 2018; Li et al. 2020; Pontes et al. 2020), which can be seen in Table. 1. We will discuss the influence of different wetting surfaces on the heat transfer enhancement mechanism in the following three sections.

From 2.1 and 2.2 section, we can see that the bubble dynamics is different on boiling surface with different wettability. In terms of the various stages of the bubble dynamics, the heterogeneous wetting surface is a relatively ideal surface. However, as shown in Table. 1, the influencing factors are complex and need further research. It is necessary to establish a general standard for the evaluation of heterogeneous wetting surface by considering the varies factors to guide the design and application of excellent boiling surface.

\subsection{Effect of the Weak Wetting Surface on Heat Transfer}

The wettability has an important effect on the superheat of bubble nucleation. Cole (1974) introduced free energy lowers the molecule $f(\theta)$ 
to propose the formula of superheat required for bubble nucleation at solid-liquid interface:

$$
\Delta T_{O N B}=\frac{T_{\text {sat }}}{\rho_{\mathrm{g}} h_{\mathrm{fg}}}\left[\frac{16 \pi \gamma_{\mathrm{lg}}{ }^{3} f(\theta)}{3 k T_{\mathrm{g}} \ln \frac{N k T_{\mathrm{g}}}{h^{\prime} J}}\right]^{1 / 2}
$$

Where $k$ is the Boltzmann's constant, $N$ is the total number of liquid molecules per unit volume, $J$ is the activation point density, and $h$ ' is the Planck's constant, respectively. The subscripts $O N B$ is refers to the onset of nucleate boiling.

For the plane surface:

$$
f(\theta)=\frac{1}{4}\left(2+3 \cos \theta-\cos ^{2} \theta\right)
$$

For $\theta=0^{\circ}, f(\theta)=1$, indicating the liquid completely wets the solid surface and the liquid superheat is equal to the homogeneous nucleation superheat. For $\theta=180^{\circ}, f(\theta)=0$, indicating the liquid completely not wets the surface and no superheat is possible. Thus, a lower onset nucleation boiling (ONB) will occur on a more hydrophobic surface (Jo et al. 2012). Jo et al. (2014) developed a new model based the thermal boundary layer, which includes the superheated liquid kinetic dynamics and the generated vapors thermodynamic stability. The model correctly depicts the trend that is increasing superheat for bubble nucleation as the contact angle decreases, which also has a good agreement with the experimental results. In addition, Li et al. (2015) explored the effect of the heating surface wettability on flow boiling heat transfer by a hybrid thermal lattice Boltzmann model. They found that an increasing contact angle will reduce the critical heat flux $(\mathrm{CHF})$ and wall superheat at ONB. According to the Hsu's (1962) boiling inception standard (equation 6), there should be a cavity on the boiling surface, which should not be submerged by liquid. However, the cavity will be submerged by liquid on superhydrophilic surface at low heat flux, which is not conducive to bubble nucleation and delay the onset of nucleation boiling:

$$
\begin{aligned}
& \left\{R r_{\min }, R r_{\text {max }}\right\}=\frac{\delta_{t} \sin \theta\left(T_{\mathrm{w}}-T_{\text {sat }}\right)}{2(1+\cos \theta)\left(T_{\mathrm{w}}-T_{1}\right)} \times \\
& {\left[1 \mp \sqrt{1-\frac{8(1+\cos \theta) \gamma_{\mathrm{gg}} T_{\text {sat }}\left(T_{\mathrm{w}}-T_{1}\right)}{\rho_{\mathrm{g}} h_{f g} \delta_{t}\left(T_{\mathrm{w}}-T_{\text {sat }}\right)^{2}}}\right]}
\end{aligned}
$$

Where $R r$ is the nucleation median radius, $\delta_{t}$ is the thermal boundary layer thickness, respectively.

The boiling surface being cooled when a bubble departure the surface, which carries heat and the thermal boundary layer from the surface to the liquid (Malenkov 1971; Dhir 1998). In general, natural convection heat transfer during waiting period is low compared with boiling heat transfer. Therefore, the chain bubble generation without any bubble waiting time and early onset of nucleate boiling on the weak wetting surface at low heat flux, which directly relates with better boiling heat transfer performance as shown in Fig. 5 (a). Besides, the size range of effective nucleation point and nucleation center density will increase with the increase of contact angle and wall superheat (Hsu 1962; Basu et al. 2002). Equation 7 shows the relationship between heat transfer coefficient (HTC), nucleation point density, bubble separation diameter and bubble separation frequency (Mikic et al. 1969).

$$
\mathrm{HTC}=2\left(\pi K \rho_{1} c\right)^{1 / 2} n d^{2} f^{1 / 2}
$$

Where $K$ is the liquid thermal conductivity, $c$ is the specific heat capacity of liquid, and $n$ is the nucleation point density, respectively.

Generally speaking, the weak wetting surface have larger effective nucleation hole size range and higher nucleation center density to improve boiling heat transfer performance under low heat flux. Fedoseev et al. (2020) also showed that enhancement of heat transfer observed on weak wetting boiling surface because to the increasing nucleation site density and the decreasing boiling onset temperature by Lattice Boltzmann simulation. Meanwhile, they also analyzed the dry areas on the weak wetting surface. On the hydrophobic surface $\left(110^{\circ}<\theta \leqslant 129^{\circ}\right)$, the maximum size of the dry area with the three-phase contact line as the boundary is greatly increased compared with the bubble departure diameter. On the superhydrophobic surface, the dry area does not shrink even during the bubble departure stage and typical film boiling is observed.

On the other hand, the bubbles easy to coalesce with each other and not easy to separate on weak wetting surface, which could hinder the supplement of liquid (Myers et al. 2005) and form a steam film on the surface to promote the film boiling and deteriorate the heat transfer performance (Takata et al. 2006; Phan et al. 2009; Hsu et al. 2012) (see Fig. 5b).

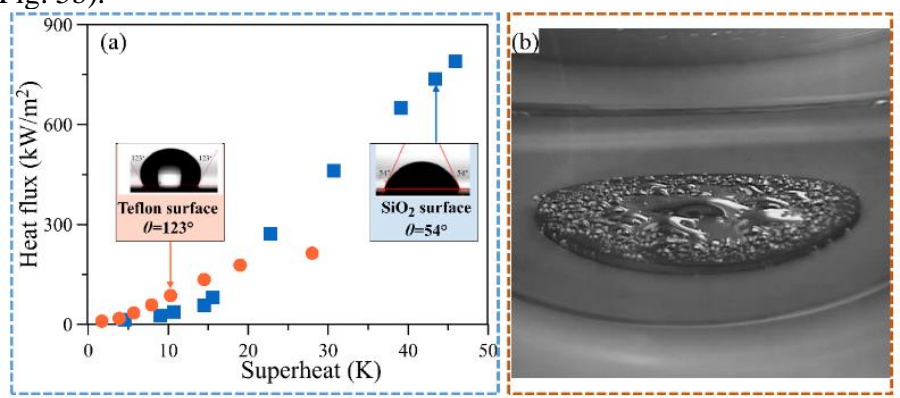

Fig. 5 (a) Comparison of boiling curve on a hydrophilic surface and hydrophobic surface (Jo et al. 2011), (b) The image of film boiling (Takata et al. 2006).

\subsection{Effect of the Strong Wetting Surface on Heat Transfer}

The strong wetting surface always has higher CHF at high heat flux, which overcomes the disadvantage of the weak wetting surface. Under the circumstances, both reversible and irreversible dry spots will be formed on the boiling surfaces, while the speed and quality of the rewetting of dry spots is motivated on strong wetting surface to delay CHF occurs (Theofanous et al. 2002). According to the dry theory, the $\mathrm{CHF}$ will occur at a nucleation site when rewetting is unable to occur at a growing dry spot (Theofanous et al. 2006; Kim et al. 2007).

The thick liquid layer drying model shown in Fig. 6 (a) (Haramura et al. 1983; Sadasivan et al. 1992). During the boiling process, the thick liquid layer will continuously absorb heat and run dry. At the same time, new bubbles grow and form mushroom steam. Thus, the thick liquid layer is supplemented. However, when the drying time of the thick liquid layer $\tau_{d}$ is less than the time for new bubbles to form mushroom steam $\tau_{h}$, CHF will occur. The relationship between the thickness $\delta_{f}$ and the drying time $\tau_{d}$ of the thick liquid layer can be expressed as (Sadasivan et al. 1992; Kim et al. 2006):

$$
\begin{gathered}
\delta_{f}=\mathrm{R}_{b}\left[\cos \theta-\frac{\pi}{12}\left(3 \cos \theta-\cos ^{3} \theta\right)\right] \\
\tau_{d}=\delta_{f} \rho_{\mathrm{l}} h_{f g} / q
\end{gathered}
$$

Where $R_{b}$ is the radius of the bubbles that are assumed to have uniform size, $q$ and $h_{f g}$ are the heat flux and evaporation heat, respectively.

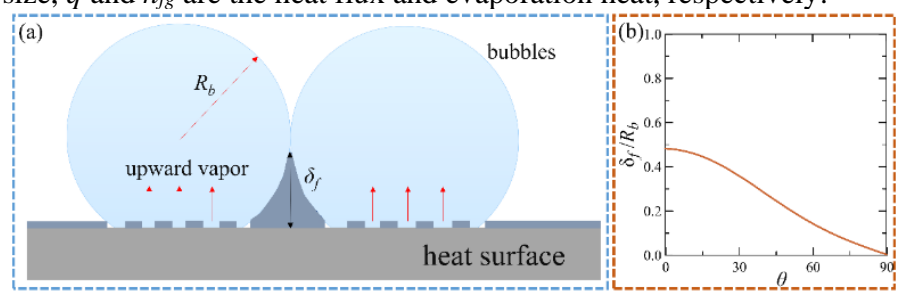

Fig. 6 (a) Schematic diagram of the thick liquid layer drying model (Sadasivan et al. 1992), (b) Liquid layer thickness vs contact angle. (Kim et al. 2006). 
From the equations (8) and (9), we can easily show the effect of surface wettability on the thickness and drying time of thick liquid layer. The lower contact angle easily lead to a thicker liquid layer and a longer drying time for given $R_{b}$ (see Fig 6b). Mukherjee et al. (2011) found that a decrease in contact angle yields the formation of liquid layer between the bubble downstream interface. The bubble with the lowest contact angle has the highest growth rate and also the highest heat transfer performance. $\mathrm{Wu}$ et al. (2020) indicated that the formation of a microfluidic layer on the strong wetting surface conducive to $\mathrm{CHF}$ improvement by molecular dynamics study.

\subsection{Effect of the Heterogeneous Wetting Surface on Heat Transfer}

The manifestation and principles of bubble dynamics and boiling heat transfer performance on the strong wetting surfaces is different with that of weak wetting surfaces. But they all have certain limitations (low CHF on weak wetting surface or posterior ONB on strong wetting surface). However, the heterogeneous wetting surface could take both the advantages of strong wetting surface and weak wetting surface by coupling various influence parameters. Wu et al. (2020) showed that a microfluidic layer could formation on the heterogeneous wetting surface by molecular dynamics study and the heterogeneous wetting surface enhances boiling heat transfer by regulating bubble behaviors.

The heterogeneous wetting surface has been one of the most development directions of boiling surface (Ahmadi et al. 2020; Qin et al. 2020; Hsu et al. 2021; Lin et al. 2021). As shown in Fig. 7, the heterogeneous wetting surface have higher HTC and CHF than the homogeneous wetting surface, which overcome the disadvantages of homogeneous wetting surface. However, as shown in Table. 1, the optimal heat transfer properties are not uniform due to the complex influencing factors of the heterogeneous wetting surface, which need further optimization design parameters to guide the composition of heterogeneous wetting surface to enhance boiling heat transfer.

Overall, the strong wetting surface has a smaller bubble separation diameter, higher separation frequency and higher CHF, but the weak wetting surface has the lower nucleation superheat and higher boiling heat transfer performance at low heat flux. For heterogeneous wetting surface, it can combine the advantages of strong wetting surface and weak wetting surface to achieve better heat transfer performance, but the combination forms are various and the influence on bubble behavior and heat transfer performance is more complex, which need further research.
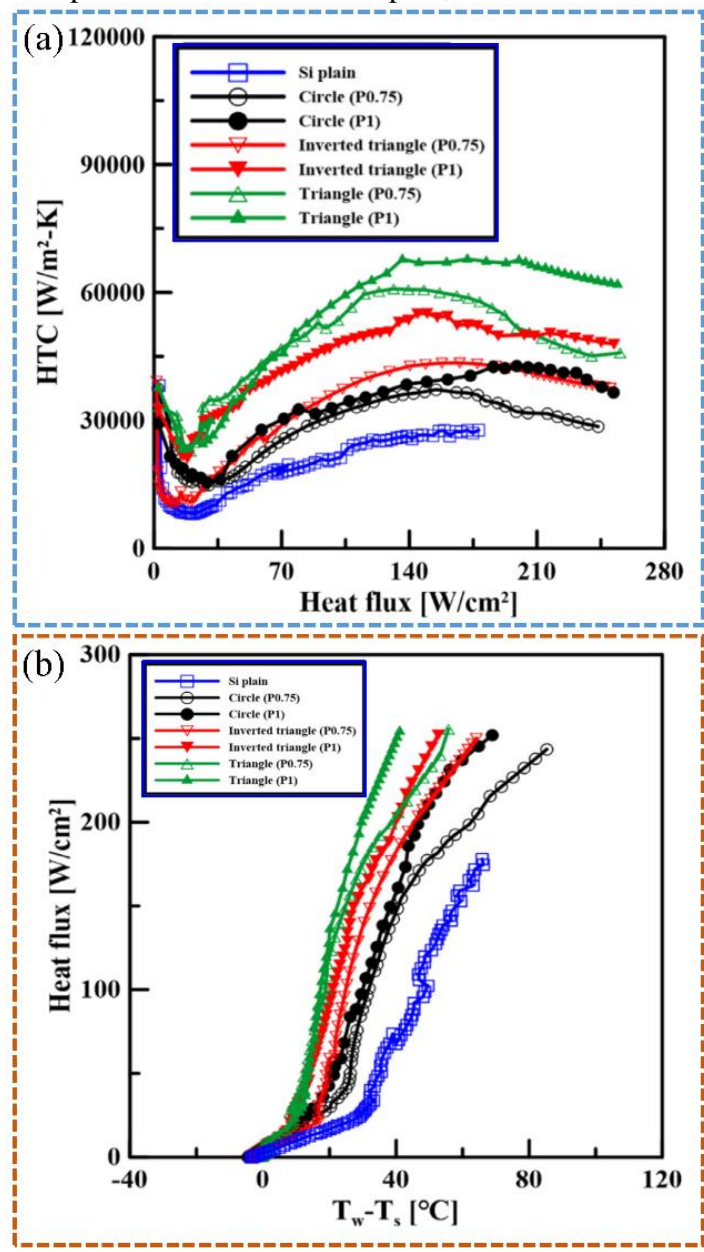

Fig. 7 (a) Relationship between wall superheat and relative heat flux and (b) Heat flux versus the HTC for various heterogeneous surfaces (Hsu et al. 2021).

Table. 1 The effect of composition parameters of heterogeneous wetting surface on bubble dynamics and heat transfer

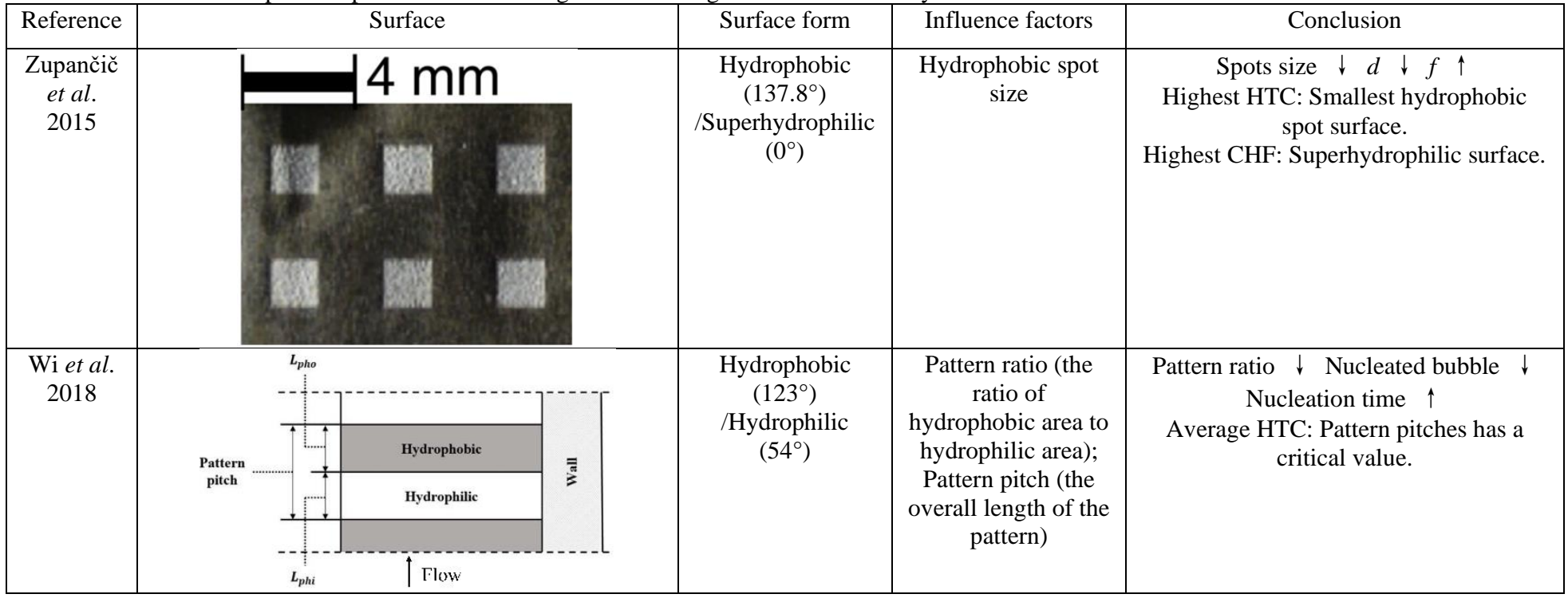




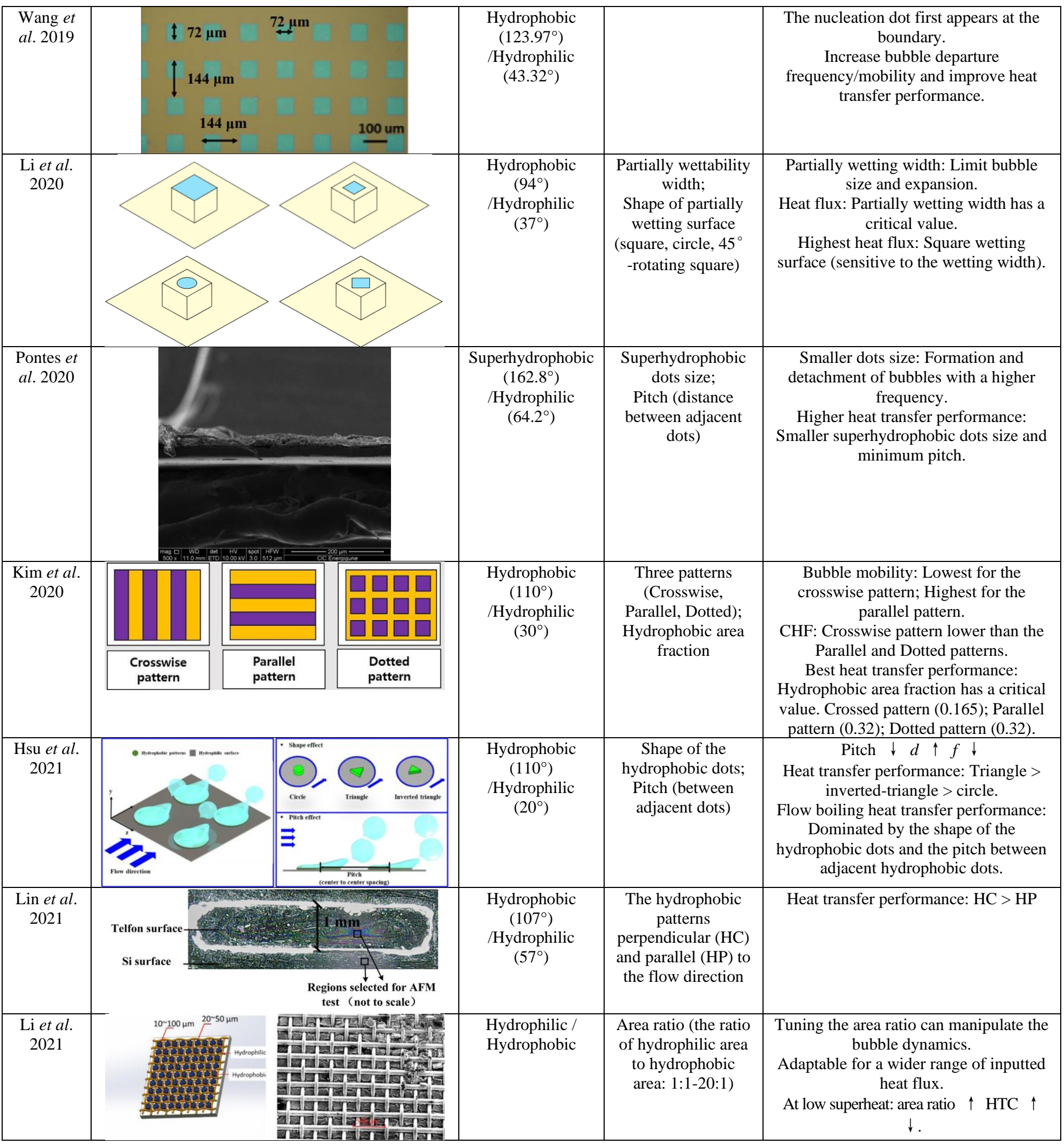

Note: $\downarrow$ refer to decrease. $\uparrow$ refer to increase. $\uparrow \downarrow$ refer to increase at first and then decrease.

\section{CONSTRUCTION METHOD AND HEAT TRANSFER ENHANCEMENT PERFORMANCE OF HOMOGENEOUS WETTING BOILING SURFACE}

Homogeneous wetting surface refer to the single wettability of the surface after a certain physical or chemical treatment, such as superhydrophilic, hydrophilic, hydrophobic and superhydrophobic. Liu et al. (2011) investigated the flow boiling characteristics of horizontal deionized water in a rectangular microchannel on silicon substrate. The basal plane is formed by the plasma etch process and has a contact angle 
of $36^{\circ}$. Then, a hydrophobic surface with a contact angle of $103^{\circ}$ is made by coating a thin layer of low surface energy material $(1 \mathrm{H}, 1 \mathrm{H}, 2 \mathrm{H}, 2 \mathrm{H}-$ Perfluoro decyltrichlorosilane). In addition, a superhydrophilic surface grown with nanowires, having a contact angle close to $0^{\circ}$, is formed by chemical vapor deposition (CVD). The results showed that the flow pattern and periodic temperature oscillation might be affected mainly by the wettability of channel surfaces. The hydrophilic surface exhibits obvious temperature fluctuation. However, periodic temperature oscillation was not found in both the hydrophobic and superhydrophilic surface.

Phan et al. (2011; 2011; 2012) studied the flow boiling characteristics of horizontal deionized water in a microchannel on a Pyrex substrate. The test channel is a single rectangular channel, which is $180 \mathrm{~mm}$ in length, $5 \mathrm{~mm}$ in width and $0.5 \mathrm{~mm}$ in height. Silicone oxide (SiOx) layer surface, Titanium (Ti) layer surface, diamond-like carbon (DLC) layer surface and carbon -doped silicon oxide (SiOC) layer surface are formed by deposition of nanoparticles through patterning masks using techniques of physical and chemical vapor depositions. These surfaces have contact angles of $26^{\circ}, 49^{\circ}, 63^{\circ}$ and $103^{\circ}$, respectively. The experimental results shown the flow boiling heat transfer is mainly dominated by surface wettability. The superheat needed for onset of nucleate boiling decreases and the total two-phase pressure drop increases when the contact angle increases. The concept of "wetting pressure drop" caused by the surface tension force generated by triple line is shown in Fig. 8 (a), which is defined as the pressure difference caused by the surface at the head and tail of the restricted bubble. As shown in equation 10 and 11, the wetting pressure drop is proportional to $(1-\cos \theta)$ (see Fig. $8 \mathrm{~b}$ ). The $\theta_{a}$ is the advancing contact angle and $\theta_{r}$ is the receding contact angle.

$$
\begin{aligned}
& \frac{d p_{\theta}}{d z}=\frac{4 \gamma_{\mathrm{lg}}\left(\cos \theta_{r}-\cos \theta_{a}\right)}{D} \frac{1}{L_{\mathrm{b}}} \\
& \frac{d p_{\theta}}{d z}=\frac{4 \gamma_{\mathrm{lg}}}{D L_{\mathrm{b}}}(1-\cos \theta)
\end{aligned}
$$

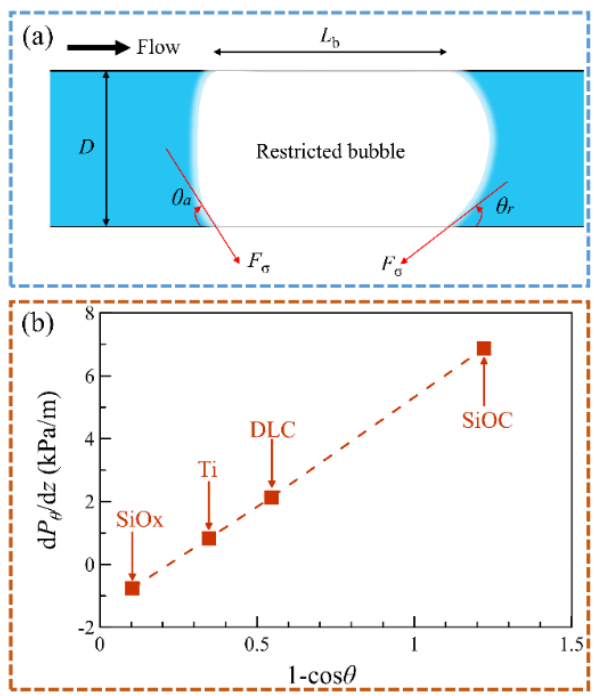

Fig. 8 (a) Wetting pressure drop model and (b) Gradient of the wetting pressure drop vs. (1- $\cos \theta)$ (Phan et al. 2011).

\subsection{Weak Wetting Surface}

For the weak wetting surface, the formation, separation and movement of bubbles are affected by the hydrophobicity of the surface, and then improve the flow boiling performance. Choi et al. (2011) used dipping method to coat a self-assembled monolayer of octadethyltrichrolosilane on a rectangular glass channel with hydraulic diameter of $500 \mu \mathrm{m}$. The test surface changed from hydrophilic to hydrophobic and the contact angle is $105^{\circ}$. The horizontal flow boiling experiment further demonstrates the important influence of surface wettability on flow pattern. The HTC of hydrophobic channel is higher than that of the hydrophilic channel, up to 1.6 times. The pressure drop of the hydrophobic channel is higher than that of the hydrophilic channel due to the large dissipation, which is caused by the motion of the triple lines in the hydrophobic channel. Sommers et al. (2013) coated a dimethyldichlorosilane hydrophobic monolayer on the laser-etched aluminum surface. According to the experimental results, the HTC on the hydrophobic surface increased by $20 \%$ than the laser-etched surface. Nedaei et al. (2017) coated the inner wall of the stainless-steel microtubule with a layer of polyperfluorodecylacrylate (pPFDA) by using chemical vapor deposition (CVD). The surface is hydrophobicity. Compared with uncoated microtubule, the HTC of flow boiling on coated microtubule can be increased by up to $61 \%$. Bottini et al. (2018) studied the flow boiling characteristics on copper surface treated by femtosecond laser in a vertical rectangular channel with a cross-section size of $12.7 \mathrm{~mm} \times 12.7 \mathrm{~mm}$. The contact angle of the treated copper surface was $131.9^{\circ}$. It was found that the CHF on the treated copper surface can be improved. However, even the prediction models including contact angle, the wettability effect of boiling surface is very complex and cannot be predicted accurately. Aravinthan et al. (2018) used electroless galvanic deposition technique to coated a hydrophobic coating on a copper tube with inner diameter of $3 \mathrm{~mm}$. The flow boiling pressure drop and the average HTC of the hydrophobic tube are higher by $15 \%$ and $40 \%$ than that of regular tube, respectively. Lin et al. (2021) fabricated a superhydrophobic structure in a rectangular channel with a hydraulic diameter of $0.91 \mathrm{~mm}$ by electroless plating. The vertical upward flow boiling experimental showed that the ONB of the superhydrophobic channel is advanced and the HTC is increased by $74.84 \%$.

\subsection{Strong Wetting Surface}

The augmentation in HTC and CHF of strong wetting surfaces is due to the wettability improvement on the surface (Gupta et al. 2018; Gupta et al. 2020). Sarwar et al. (2007) prepared three coating paint by combining $1.5 \mathrm{~g}$ of alumina (particle size, $d<10 \mu \mathrm{m})$, alumina $(d<1 \mu \mathrm{m})$ and $\mathrm{TiO}_{2}$ $(d<5 \mu \mathrm{m})$ with $0.4 \mathrm{ml}$ epoxy resin and $10 \mathrm{ml}$ isopropyl alcohol, respectively. The coating paint after stirring, heating and curing was applied inside a half-inch $(12.7 \mathrm{~mm}) \mathrm{SS} 316$ circular tube's inner surface using a spray gun. Experiments shown that the vertical flow boiling surface coating intercept more water, enhancing the surface wettability, reducing the contact angle and improving the capillary effect. Compared with smooth surface, CHF of coating surface can be increased by $20-25 \%$.

Morshed et al. (2013) studied the flow boiling performance of horizontal deionized water in a copper microchannel with hydraulic diameter of $672 \mu \mathrm{m}$. The $\mathrm{Cu}-\mathrm{Al}_{2} \mathrm{O}_{3}$ nanocomposite coating were deposited on the bottom surface of the copper microchannel by electrodeposition. Compare with bare surface, the contact angle of coated surface reduces from $97^{\circ}$ to $67^{\circ}$. The result shown that HTC of the coated surface increases by up to $100 \%$ than the bare surface. The CHF of the $\mathrm{Cu}-\mathrm{Al}_{2} \mathrm{O}_{3}$ nanocomposite coated surface increases $35-55 \%$ due to the increased wettability of the coated surface promotes the diffusion of the liquid into the dry zone. Subsequently, $\mathrm{Al}_{2} \mathrm{O}_{3}$ nanoparticle was deposited on the bottom surface of the copper microchannel by the nanoparticle self-deposition method (Morshed et al. 2013). The surface wettability was enhanced and the contact angle reduce from $97^{\circ}$ to $57^{\circ}$. Compared with the bare surface microchannel, the $\mathrm{CHF}$ of $\mathrm{Al}_{2} \mathrm{O}_{3}$ nanoparticle coated surface was up to $39 \%$ enhancement, which lower than the CHF enhancement effect on the surface constructed by electrodeposition method. That is due to the stability of surface constructed by nanoparticle self-deposition method is poor, especially at high mass flux (see Fig.9a). The CHF enhancement mechanism is presented as shown in Fig. 9(b). In bubbly flow, coating of the nanoparticles promotes the liquid flow under the bubble to delay the formation of vapor blanket on the $\mathrm{Cu}$ surface. Therefore, the CHF of nanoparticles coated surface is higher than that of bare surface. In addition, Sujith Kumar et al. $(2015 ; 2016)$ provides 
experimental studies on $\mathrm{Fe}$ doped $\mathrm{Al}_{2} \mathrm{O}_{3}-\mathrm{TiO}_{2}$ coating surface and sodium dodecyl sulfate (SDS) doped $\mathrm{ZnO}-\mathrm{Al}_{2} \mathrm{O}_{3}$ coating surface by spray pyrolysis technique on sand blasted copper surface, respectively. The hydrophilicity of coating surfaces increases with the increase in $\mathrm{Fe}$ and SDS doping. The boiling performance for $7.2 \% \mathrm{Fe}$ doped surface was the best, HTC and CHF increased by $44.11 \%$ and $52.39 \%$, respectively. Besides, HTC and CHF increased by $29.7 \%$ and $44.6 \%$ for the 4 wt. $\%$ SDS added $\mathrm{ZnO}_{-} \mathrm{Al}_{2} \mathrm{O}_{3}$ surface. Gupta et al. (2021) used single-step forced convection electrochemical deposition followed by single-step sintering to fabricate $\mathrm{Cu}-\mathrm{TiO}_{2}$ coating on copper boiling surface. Compare with bare surface, the contact angle of coated surface reduces from $65^{\circ}$ to $38^{\circ}$. The flow boiling experiment showed the HTC and $\mathrm{CHF}$ increased by $143 \%$ and $153 \%$ than the bare copper surface. Then, they fabricate $\mathrm{Cu}-\mathrm{Al}_{2} \mathrm{O}_{3}$ coating copper surface by four-step (deposition-sintering-deposition-sintering), which surface wettability is enhanced (Gupta et al. 2021). Compare with bare surface, the ONB decreased by $5.2 \mathrm{~K}$. The HTC and CHF increased by $200 \%$ and $176 \%$, respectively.
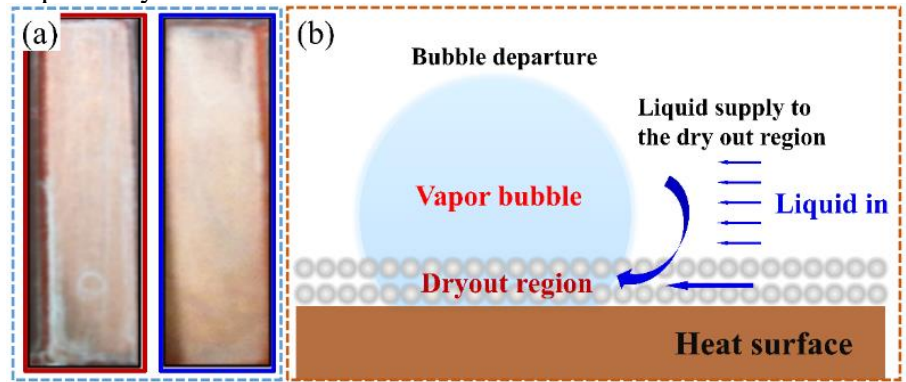

Fig. 9 (a) The images of $\mathrm{Al}_{2} \mathrm{O}_{3}$ coated $\mathrm{Cu}$ surface after the deposition (left) and at the end of boiling experiment (right) and (b) The CHF enhancement mechanism in nanoparticles coated surface (Morshed et al. 2013).

Yang et al. (2013; 2014; 2014) introduced an electroless electrochemical etching technique to directly grow silicon nanowires (SiNW) on the bottom and vertical walls of the silicon rectangular microchannel. The wall surfaces were modified into superhydrophilic can get the best wettability (the contact angles were close to $0^{\circ}$ ). The flow boiling experiments showed that the superhydrophilic surface are more likely to produce small bubbles and the direction of the dominant surface tension force can be transferred from the cross-sectional plane to the inner-wall plane, as shown in Fig 10 (a), which can be simplified the multiple flow boiling regimes into a single annular flow. At the same time, the strong capillarity force of the superhydrophilic SiNW structure accelerates the liquid rewetting. Thus, the nuclear boiling on the downstream wall of the channel can be transmitted to thin film evaporation and liquid film renewal to improve local drying, as shown in Fig. 10 (b). In addition, the high capillary force provided by the superhydrophilic surface can flat the liquid-vapor interface fluctuation and make the vapor-liquid separation more obvious under a single annular flow. In conclusion, the superhydrophilic surface not only can eliminate the uncertainty of flow pattern transition, but also improve the flow boiling performance. The average HTC was enhanced by up to $326 \%$, the CHF was increased by $300 \%$, and the frictional pressure drop was reduced by $48 \%$, respectively.

On the other hand, the two-phase flow pattern in flow boiling is dominated by many factors, such as bubble motion, surface tension, liquid-vapor interaction, of which the combination effect that results in flow instabilities. Using the inlet restrictor can restrain flow boiling instabilities, but the pressure drop increase too much. However, it is surprising that changing the wettability of the surface and making it superhydrophilic can improve the flow boiling flow pattern to suppress the flow stability and improve the flow boiling performance (Yang et al. 2014; Li et al. 2012; Ahn et al. 2012).

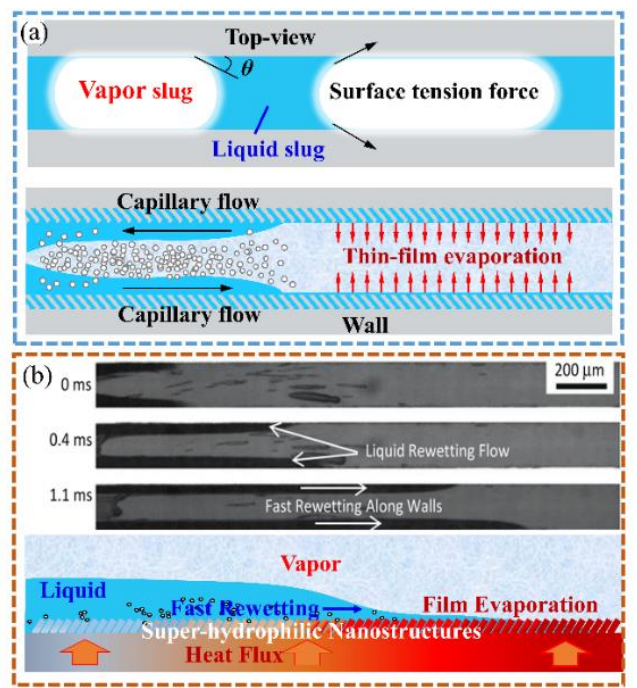

Fig. 10 (a) The schematic of the flow structure in a microchannel with smooth or superhydrophilic wall (Yang et al. 2013), (b) Liquid rapid rewetting visualization image and heat transfer mechanism schematic diagram (Yang et al. 2014).

\section{CONSTRUCTION METHOD AND ENHANCEMENT FLOW BOILING PERFORMANCE OF HETEROGENEOUS WETTING BOILING SURFACE}

With the deepening of research on flow boiling, the following requirements have been identified for a good boiling surface: the smaller initial wall superheat of boiling and flow boiling pressure drop loss; enhance boiling surface stability; the higher HTC and CHF. However, a single homogeneous wetting surface cannot embrace the above conditions. The heterogeneous wetting surface can combine the advantages of strong wetting surface and weak wetting surface, which has excellent heat transfer performance for flow boiling (Nedaei et al. 2016).

Kousalya et al. (2015) reported the horizontal subcooled flow boiling characteristics on the heterogeneous wetting surfaces (superhydrophilic - superhydrophobic) in a rectangular channel with a height of $5.5 \mathrm{~mm}$, as shown in Fig. 11. The heterogeneous wetting surface are shaped with alternating parallel stripes of superhydrophilic and superhydrophobic regions using graphitic petal-decorated carbon nanotube (GPCNT) coating. A combination of Teflon coating, shadow mark, and oxygen plasma treatment is used to form composite heterogeneous wetting surfaces with differing superhydrophilic fractions. The superhydrophilic fractions are $0,0.35,0.66,0.85$ and 1 , respectively. The superhydrophobic region of the heterogeneous wetting surfaces was the first to nucleate and form a near-spherical isolated bubble, which promoted the evaporation of the thin film. Meanwhile, in coordination with the surrounding superhydrophilic region, the bubble boiling cycle was enhanced and the boiling thermal performance was improved. The initial boiling superheat of the heterogeneous wetting surfaces is generally lower than that of the homogeneous wettability surfaces.

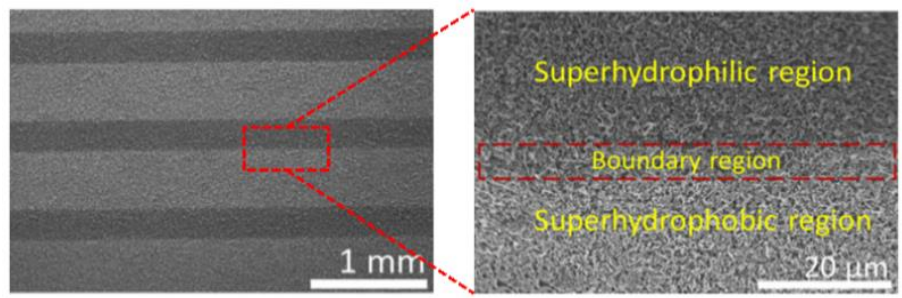

Fig. 11 The SEM images of the heterogeneous wetting surface (superhydrophilic-dark gray colored regions; superhydrophobic-light gray colored regions) (Kousalya et al. 2015). 
Wang et al. (2017) prepared polytetrafluoroethylene hydrophobic hexagon points with side length of $30 \mu \mathrm{m}$ and pitch distance of $60 \mu \mathrm{m}$ on the hydrophilic $\mathrm{SiO}_{2}$ surface by using etching technique. The contact angles of the hydrophilic surface and the hydrophobic point are $33^{\circ}$ and $120^{\circ}$, respectively. The reflux can be caused by the hydrophilic action around the hydrophobic point to improve the boiling heat transfer performance. The initial superheat of boiling on the heterogeneous wetting surface decreased by about $6{ }^{\circ} \mathrm{C}$ and the HTC increased by $70 \%$ than that on the hydrophilic surface. In addition, He et al. (2017) established an analytical model of the minimum local forces on a threephase line to analyze bubble departure/movement in microchannels. As shown in Equation 12,s、 $\gamma_{\mathrm{lg}} 、 \theta_{\mathrm{r}} 、 \theta_{\mathrm{a}} 、$ philic $、$ phobic $、 \Delta 、 H_{r}$ represents the three-phase line length, surface tension, receding contact angle, advancing contact angle, hydrophilic surface, hydrophobic surface, hydrophilic surface area fraction and adhesive force due to microscale surface roughness and heterogeneity, respectively. It indicates the minimum local force requirement for bubble to leave the heterogeneous wetting surface is less than that of the homogeneous hydrophobic surface.

$$
F_{\mathrm{h}}=s \gamma_{\mathrm{lg}}\left(\begin{array}{l}
\left(\cos \theta_{\mathrm{r}, \text { philic }}-\cos \theta_{\mathrm{a} \text {,philic }}\right) \Delta+ \\
\left(\cos \theta_{\mathrm{r}, \text { phobic }}-\cos \theta_{\text {a,phobic }}\right)(1-\Delta)+H_{r}
\end{array}\right)
$$

In a word, the heat transfer enhancement performance is different on the heterogeneous wetting surface with different combination forms and the homogeneous wetting surfaces. Table. 2 lists the forms, construction methods and enhanced heat transfer effect of representative boiling surfaces. We can clearly see that the heat transfer performance is very diversity, now lack of a consensus theory to explain underlying mechanisms of surface morphology and properties on heat transfer enhancement, so it is still to perfect and enrich in the further.

Table. 2 Construction method of different wetting surfaces and heat transfer of flow boiling

\begin{tabular}{|c|c|c|c|c|c|}
\hline Surface & Reference & Test channel & Surface & Construction method & Heat transfer enhancement effect \\
\hline \multirow[t]{4}{*}{$\begin{array}{l}\text { Weak } \\
\text { wetting } \\
\text { surface }\end{array}$} & $\begin{array}{l}\text { Sommers et } \\
\text { al. } 2013\end{array}$ & $\begin{array}{c}\text { Microchannel } \\
10 \mu \mathrm{m} \times 50 \mu \mathrm{m} \times 6 \\
2 \mathrm{~mm}\end{array}$ & $\begin{array}{l}\text { Laser-etched surface } \\
\qquad\left(69.5^{\circ}\right) \\
\text { Dimethyldichlorosilane } \\
\text { coating surface }\left(108^{\circ}\right)\end{array}$ & Dipping & $\begin{array}{c}* \\
\mathrm{HTC} \uparrow 20 \%(*)\end{array}$ \\
\hline & $\begin{array}{l}\text { Nedaei et } \\
\text { al. } 2017\end{array}$ & $\begin{array}{c}\text { Microtube } \\
\text { Inner diameter } \\
889 \mu \mathrm{m}\end{array}$ & $\begin{array}{l}\text { Bare surface }\left(61^{\circ}\right) \\
\text { Polyperfluorodecylacry } \\
\text { late (pPFDA) coating } \\
\text { surface }\left(106^{\circ}\right)\end{array}$ & $\begin{array}{c}- \\
\text { Chemical vapor deposition } \\
\text { (CVD) }\end{array}$ & $\begin{array}{c}* * \\
\mathrm{HTC} \uparrow 61 \%(*)\end{array}$ \\
\hline & $\begin{array}{l}\text { Bottini et } \\
\text { al. } 2018\end{array}$ & $\begin{array}{c}\text { Rectangular } \\
\text { channel } \\
12.7 \times 12.7 \times 107 \\
95 \mathrm{~mm} \\
\end{array}$ & $\begin{array}{l}\text { Bare } \mathrm{Cu} \text { surface }\left(58.7^{\circ}\right) \\
\text { Textured surface } \\
\left(131.9^{\circ}\right)\end{array}$ & $\begin{array}{c}- \\
\text { femto-second laser }\end{array}$ & $\begin{array}{c}* \\
\mathrm{CHF} \downarrow(*)\end{array}$ \\
\hline & $\begin{array}{l}\text { Lin et al. } \\
2021\end{array}$ & $\begin{array}{l}\text { Microchannel } \\
\text { Hydraulic } \\
\text { diameter } \\
0.91 \mathrm{~mm} \\
0.5 \times 5 \times 80 \mathrm{~mm} \\
\end{array}$ & $\begin{array}{l}\text { Bare } \mathrm{Cu} \text { surface }\left(75^{\circ}\right) \\
\text { Test surface }\left(150^{\circ}\right)\end{array}$ & $\begin{array}{c}- \\
\text { Electroless Plating }\end{array}$ & $\begin{array}{c}* \\
\mathrm{ONB} \downarrow(*) ; \operatorname{HTC} \uparrow 74.84 \%(*)\end{array}$ \\
\hline \multirow[t]{4}{*}{$\begin{array}{l}\text { Strong } \\
\text { wetting } \\
\text { surface }\end{array}$} & $\begin{array}{l}\text { Morshed et } \\
\text { al. } 2013\end{array}$ & $\begin{array}{l}\text { Microchannel } \\
\text { Hydraulic } \\
\text { diameter } \\
672 \mu \mathrm{m} \\
0.36 \times 5 \times 26 \mathrm{~mm}\end{array}$ & $\begin{array}{l}\text { Bare } \mathrm{Cu} \text { surface }\left(97^{\circ}\right) \\
\mathrm{Cu}-\mathrm{Al}_{2} \mathrm{O}_{3} \text { coating } \\
\text { surface }\left(67^{\circ}\right) \\
\mathrm{Al}_{2} \mathrm{O}_{3} \text { coating surface } \\
\left(57^{\circ}\right)\end{array}$ & $\begin{array}{l}\text { Electrodeposition } \\
\text { technique } \\
\text { Self-deposition of } \\
\text { nanoparticles } \\
\end{array}$ & $\begin{array}{c}* \\
\mathrm{ONB} \downarrow 8^{\circ} \mathrm{C}(*) ; \mathrm{HTC} \uparrow 100 \%(*) ; \quad \mathrm{CHF} \\
\uparrow 55 \%(*) ; \mathrm{PDP} \rightarrow(*) \\
\mathrm{HTC} \rightarrow(*) ; \mathrm{CHF} \uparrow 39 \%(*)\end{array}$ \\
\hline & $\begin{array}{l}\text { Sujith } \\
\text { Kumar et } \\
\text { al. } 2015- \\
2016\end{array}$ & $\begin{array}{c}\text { Microchannel } \\
0.4 \times 20 \times 30 \mathrm{~mm}\end{array}$ & $\begin{array}{c}\text { Bare } \mathrm{Cu} \text { surface }\left(75.5^{\circ}\right) \\
\mathrm{Fe} \text { doped } \mathrm{Al}_{2} \mathrm{O}_{3}-\mathrm{TiO}_{2} \\
\text { composite coating } \\
\text { surface }\left(40.1^{\circ}\right) \\
\mathrm{ZnO} \text { surface } \\
\mathrm{SDS} \text { (sodium dodecyl } \\
\text { sulfate) doped } \mathrm{ZnO}- \\
\mathrm{Al}_{2} \mathrm{O}_{3} \text { composite } \\
\text { coating surface }\left(32.9^{\circ}\right) \\
\end{array}$ & $\begin{array}{l}\text { - } \\
\text { Spray pyrolyzed } \\
\text { - } \\
\text { Spray pyrolyzed }\end{array}$ & $\begin{array}{c}\text { HTC } \uparrow 44.11 \%(*) ; \quad \text { CHF } \uparrow 52.39 \%(*) \\
\text { HTC } \uparrow 29.7 \%(\#) ; \quad \text { CHF } \uparrow 44.6 \%(\#)\end{array}$ \\
\hline & $\begin{array}{c}\text { Gupta et al. } \\
2021\end{array}$ & $\begin{array}{l}\text { Horizontal } \\
\text { minichannel }\end{array}$ & $\begin{array}{c}\text { Bare surface }\left(65^{\circ}\right) \\
\mathrm{Cu}-\mathrm{Al}_{2} \mathrm{O}_{3} \text { surface }\left(32^{\circ}\right)\end{array}$ & $\begin{array}{c}- \\
\text { Four-step electrodeposition } \\
\text { technique (deposition- } \\
\text { sintering-deposition- } \\
\text { sintering) }\end{array}$ & $\begin{array}{c}* \\
\mathrm{ONB} \downarrow(5.2 \mathrm{~K}) ; \mathrm{HTC} \uparrow 200 \%(*) ; \quad \mathrm{CHF} \\
\uparrow 176 \%(*)\end{array}$ \\
\hline & $\begin{array}{l}\text { Yang et al. } \\
\text { 2013-2014 }\end{array}$ & $\begin{array}{l}\text { Microchannel } \\
1 \times 10 \times 30 \mathrm{~mm}\end{array}$ & $\begin{array}{l}\text { Plain-wall surface } \\
\text { Silicon nanowire } \\
\text { surface }\left(0^{\circ}\right)\end{array}$ & $\begin{array}{l}\text { Deep reactive ion etching } \\
\text { (DRIE) } \\
\text { Electroless electrochemical } \\
\text { etching technique }\end{array}$ & $\begin{array}{c}\mathrm{HTC} \uparrow 326 \%(*) ; \quad \mathrm{CHF} \uparrow 300 \%(*) ; \\
\mathrm{PDP} \downarrow 48 \%(*)\end{array}$ \\
\hline $\begin{array}{l}\text { Heterog } \\
\text { eneous } \\
\text { wetting } \\
\text { surface }\end{array}$ & $\begin{array}{l}\text { Kousalya et } \\
\text { al. } 2015\end{array}$ & $\begin{array}{l}\text { Rectangular } \\
\text { channel } \\
5.5 \mathrm{~mm}\end{array}$ & $\begin{array}{l}\text { Superhydrophilic } \\
\text { surface } \\
\text { Superhydrophobic / } \\
\text { Superhydrophilic } \\
\text { surface } \\
\end{array}$ & $\begin{array}{c}\text { Two-step microwave } \\
\text { plasma enhanced chemical } \\
\text { vapor deposition technique }\end{array}$ & $\begin{array}{c}\mathrm{ONB} \downarrow(*) ; \mathrm{HTC} \uparrow 50 \%(*) ; \quad \mathrm{CHF} \uparrow \\
14 \%(*)\end{array}$ \\
\hline
\end{tabular}




\begin{tabular}{|c|c|c|c|c|}
\hline & & $\left(0^{\circ} / 162^{\circ}\right)$ & $\begin{array}{l}\text { Teflon coating, shadow } \\
\text { mask, oxygen plasma } \\
\text { treatment }\end{array}$ & \\
\hline $\begin{array}{l}\text { Wang et al. } \\
2017\end{array}$ & Microchannel & $\begin{array}{l}\text { Bare silicon surface } \\
\text { Polytetrafluoroethylene } \\
\text { hydrophobic hexagon } \\
\text { points / hydrophilic } \\
\mathrm{SiO}_{2} \text { surface }\left(120^{\circ} / 33^{\circ}\right)\end{array}$ & $\begin{array}{c}- \\
\text { Etching technique }\end{array}$ & $\begin{array}{c}* \\
\mathrm{ONB} \downarrow 6^{\circ} \mathrm{C}(*) ; \mathrm{HTC} \uparrow 70 \%(*) ; \quad \mathrm{CHF} \\
\uparrow 55 \%(*)\end{array}$ \\
\hline $\begin{array}{l}\text { Hsu et al. } \\
\quad 2021\end{array}$ & $\begin{array}{l}\text { Rectangular } \\
\text { channel } \\
5 \times 5 \times 93.8 \mathrm{~mm}\end{array}$ & $\begin{array}{l}\text { Si surface }\left(40^{\circ}\right) \\
\text { Flurooctytrichlorosilan } \\
\text { e/Silica surface } \\
\left(110^{\circ} / 20^{\circ}\right)\end{array}$ & $\begin{array}{l}- \\
\text { Micro-electrical- } \\
\text { mechanical systems } \\
(\text { MEMS })\end{array}$ & $\begin{array}{c}* \\
\mathrm{HTC} \uparrow 163 \%\left({ }^{*}\right) ; \mathrm{CHF} \uparrow 43 \%(*)\end{array}$ \\
\hline $\begin{array}{l}\text { Lin et al. } \\
\quad 2021\end{array}$ & $\begin{array}{l}\text { Rectangular } \\
\text { channel } \\
\text { Hydraulic } \\
\text { diameter } \\
0.91 \mathrm{~mm}\end{array}$ & $\begin{array}{c}\text { Silicon surface } \\
\text { Teflon/Silica surface } \\
\left(107^{\circ} / 57^{\circ}\right)\end{array}$ & $\begin{array}{l}\text { Masking, spin coating, } \\
\text { bake }\end{array}$ & $\begin{array}{c}* \\
\mathrm{HTC} \uparrow 39.55 \%(*) ; \mathrm{PDP} \downarrow\left(^{*}\right)\end{array}$ \\
\hline
\end{tabular}

Note: *, \# refer to the compare surface. $\downarrow$ refer to decrease. $\uparrow$ refer to increase. $\rightarrow$ refer to little change. PDP refer to pressure drop penalty. HTC and $\mathrm{CHF}$ are the best value in each experiment.

\section{Intelligent wettability surfaces with adaptive functions}

The intelligent wetting surface can also be considered as a kind of heterogeneous wetting surface. However, the heterogeneous wetting surfaces mentioned above often have two kinds of wettability from the beginning, while the intelligent wetting surface realizes its own wettability transformation through external stimulation, which can be matched with the requirements of the working process. For intelligent wetting surface, the surface material is important. The external stimuli that can be perceived by the responsive wettability surface materials include light signal, temperature, pressure, $\mathrm{PH}$ value, electric field, etc. However, the pressure, $\mathrm{PH}$ value, electric field and other response methods are difficult to be applied to the boiling process due to the problems of surface ductility, phase change working medium and applicable scale. The intelligent wetting surface with optical signal and temperature response has been studied.

It has been proved that the wettability of $\mathrm{TiO}_{2}$ surface is improved after ultraviolet (UV) irradiation (Sun et al. 2001), which due to the water molecules preferentially adsorb at the light-generated defect sites on the surface. Then, Takata et al. (2005) manipulated the contact angle of $\mathrm{TiO}_{2}$ surface by UV light only. The experiment showed the $\mathrm{TiO}_{2}$ coating surface has better heat transfer performance than bare surface. Zhang et al. (2017) indicated the contact angle of $\mathrm{TiO}_{2}$ surface decreases with the increase of UV irradiation time, while the CHF increases by $67 \%$ than that on untreated surface. However, these studies only focus on pool boiling and have not been involved in flow boiling. In addition, the violent action of the vapor-liquid interface in the boiling process will also affect the experimental conditions and hinder its application in flow boiling.

It is necessary to select suitable surface materials with adaptive function based on temperature, which should be an important direction to adjust the wettability of intelligent surface. Meng et al. (2005) and Zheng et al. (2014) reported that the wettability transformation of $\mathrm{ZnO}$ and $\mathrm{TiO}_{2}$ surfaces are related to temperature. Kim et al. (2017) deposited $\mathrm{SiO}_{2}$ layer as the reference surface (SCS) by thermal growth. Then, used radio frequency sputtering to deposited a $\mathrm{TiO}_{2}$ layer on the $\mathrm{SiO}_{2}$ thin film as the text surface (TCS). The TCS showed stronger wettability than SCS with increasing temperature (heat treatment temperature $>160{ }^{\circ} \mathrm{C}$ ) as shown in Fig. 12 (a). They indicated that the HTC of TCS was higher than SCS at all experimental conditions, while the TCS had higher CHF only at high-wall-superheat as shown in Fig. 12 (b). Then, they further studied the time effect of wetting transition on $\mathrm{TiO}_{2}$ coated surface (Kim et al. 2017). The TCS showed stronger wettability than SCS with increasing time (heat treatment time $>2 \mathrm{~h}$ ). In addition, they examined the HTC and CHF in flow boiling on $\mathrm{TiO}_{2}$ and $\mathrm{ZnO}$ coated surface, which called intelligent wetting surface. The $\mathrm{ZnO}$ coated surface also had properties similar to those of TCS. They reported this kind of surface had a higher HTC in low-wall-superheat region due to its hydrophobicity and higher CHF (Kim et al. 2017). However, this kind surface only works at higher wall-superheat and saturation boiling temperature, which limit its application.

Due to the lower critical solution temperature (LCST), temperature responsive polymer coating can also be used to construct intelligent wetting surfaces. When the temperature increases from less than LCST to more than LCST, the surface wettability changes from hydrophilic to hydrophobic. Bertossi et al. (2015) reported that the experimental results validate the assumption that polymers coating surface enhance heat transfer in nucleate boiling conditions. The transition of the hydrophilic and hydrophobic state of the polymers coating surface promotes the bubble formation (hydrophobic surface) and bubble departure (hydrophilic surface).
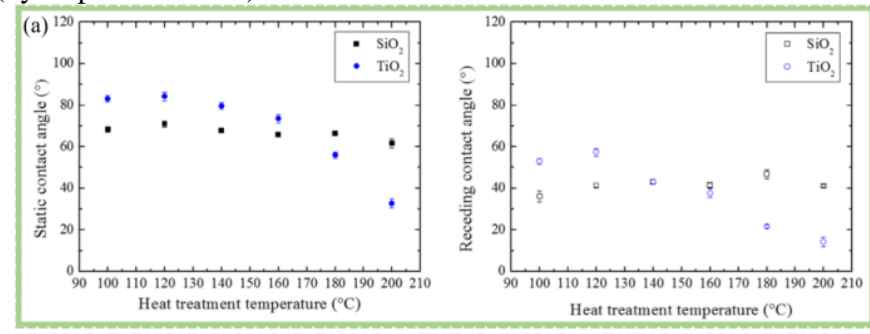

(b)
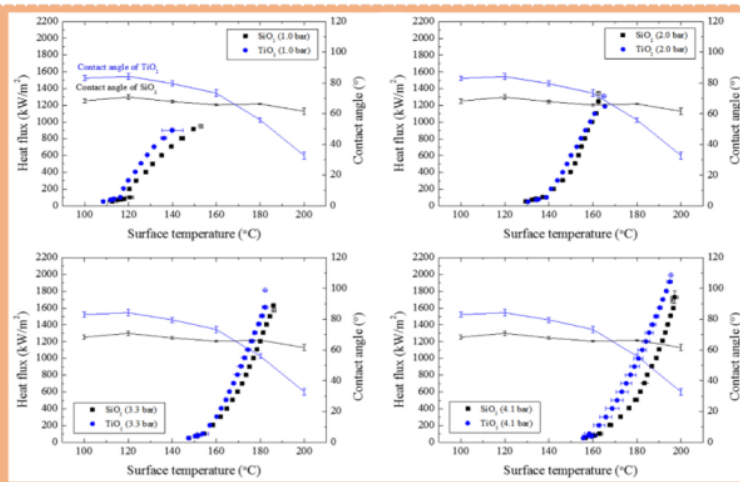

Fig. 12. (a) Measured static contact angles and receding contact angles after heat treatment and (b) The heat fluxes and contact angles vs wall temperature at different pressures (Kim et al. 2017).

As can be seen from the first two chapters, surface wettability plays an important role in the boiling process (from bubble dynamics to overall heat transfer performance). However, it should be noted that the 
wettability requirement for a good boiling surface is dynamic at different periods of bubble dynamics or different boiling conditions. The intelligent wetting surface can meet the dynamic requirements, but the selection of surface materials and the design of transition temperatures need more research. It is still a challenge to strike a balance between materials, working medium, surface properties and experimental conditions to achieve optimal boiling performance. Therefore, it is necessary to expand the relevant basic experimental data to guide the design of intelligent wetting surface.

\section{CONCLUSIONS}

In summary, the weak wetting surface can be fabricated by physical, chemical method or coating the original surface with a layer of low surface energy. Thus, it has more effective activation point and nucleation center density, then the boiling heat transfer coefficient can be increased at low heat flux. The strong wetting surface formed by physical or chemical treatment can provide strong capillary force to promote the rapid rewetting of the wall surface and delay CHF. Both advantages of boiling heat transfer on strong wetting surface and weak wetting surface can be integrated in heterogeneous wetting surface. Nevertheless, the composition of heterogeneous wetting surface is diversity and it is complicated in mechanism, which needs further study.

Surface wettability has an important influence on flow boiling heat transfer. However, some surfaces cannot maintain wettability stably, and surface stability has been rarely reported. Therefore, the development of surfaces with strong stability and high boiling heat transfer performance should be of concern. The wettability of boiling surfaces also affects the flow patterns and the transition between flow patterns. It is significant for the further development to fabricate effective wettability on boiling surface and realize the synergistic effect of flow pattern and heat transfer.

The development of intelligent wettability surfaces with adaptive functions is essential for further improvement of boiling performance. How to match the temperature control materials and wettability transition temperature of the intelligent wettability surface with the experimental working conditions should also be paid attention. Other types of novel intelligent materials/surfaces also need to be developed or prepared to further improve boiling heat transfer under different operating conditions.

In addition, the flow boiling channel can be divided into micro, small and conventional channels according to the channel size (Kandlikar et al. 2002). In recent years, the research on wettability of flow boiling mainly focuses on micro and small channels, and less is involved in conventional channels with channel size greater than $3 \mathrm{~mm}$. As the improving of surface processing technology, it is necessary to strengthen the research on the effect of surface wettability on the flow boiling performance for conventional channel.

\section{ACKNOWLEDGEMENTS}

The study was supported by the National Natural Science Foundation of China (51906231), Henan Provincial Department of Science and Technology Research Project (212102310096), Foundation of Henan Educational Committee (20A470012), and the Maker Space Incubation Project of Zhengzhou University of Light Industry (2019ZCKJ106).

\section{NOMENCLATURE}

c specific heat capacity of liquid $(\mathrm{J} /(\mathrm{kg} \cdot \mathrm{K}))$

C independent parameter

$d \quad$ the bubbles departure diameter $(\mathrm{m})$

$D \quad$ hydrodynamic diameter (m)

$f \quad$ the bubbles departure frequency

$f(\theta) \quad$ free energy lowers the molecule

$F \quad$ depinning force $(\mathrm{N})$

$g \quad$ gravity force $\left(\mathrm{m} / \mathrm{s}^{2}\right)$

$\begin{array}{ll}h_{f g} & \text { evaporation heat }(\mathrm{J} / \mathrm{kg}) \\ h & \text { Planck's constant }(\mathrm{J} \cdot \mathrm{s}) \\ H_{r} & \text { adhesive force }(\mathrm{N}) \\ J & \text { activation point density per unit volume }\left(\# / \mathrm{m}^{3}\right) \\ k & \text { Boltzmann's constant }(\mathrm{J} / \mathrm{K}) \\ K & \text { liquid thermal conductivity }(\mathrm{W} /(\mathrm{m} \cdot \mathrm{K})) \\ L & \text { length }(\mathrm{m}) \\ n & \text { nucleation point density } \\ N & \text { number of liquid molecules per unit volume }\left(\# / \mathrm{m}^{3}\right) \\ P & \text { pressure }(\mathrm{Pa}) \\ q & \text { heat flux }\left(\mathrm{W} / \mathrm{m}^{2}\right) \\ r & \text { surface roughness factor } \\ R_{b} & \text { the radius of assumed bubbles (m) } \\ R_{r} & \text { nucleation median radius (m) } \\ S & \text { three-phase line length (m) } \\ T & \text { temperature }(\mathrm{K}) \\ \delta_{f} & \text { thickness of the thick liquid layer }(\mathrm{m}) \\ \delta_{t} & \text { thermal boundary layer thickness }(\mathrm{m}) \\ \tau_{d} & \text { drying time of the thick liquid layer }(\mathrm{s}) \\ \tau_{h} & \text { time for new bubbles to form mushroom steam }(\mathrm{s}) \\ \Delta & \text { hydrophilic surface area fraction } \\ \Delta T & \text { temperature difference (K) }\end{array}$

Greek Symbols

$\theta \quad$ contact angle $\left({ }^{\circ}\right)$

$\gamma \quad$ surface tension force $(\mathrm{N} / \mathrm{m})$

$\rho \quad$ density $\left(\mathrm{kg} / \mathrm{m}^{3}\right)$

$\sigma \quad$ surface tension (N/m)

Subscripts

a advancing

g gas

$h \quad$ heterogeneous surface

$l \quad$ liquid

$\max \quad$ maximum

min minimum

$O N B \quad$ the onset of nucleate boiling

philic hydrophilic surface

phobic hydrophobic surface

$r$ receding

$s \quad$ solid

sat saturation

w wall

$\theta \quad$ wetting

\section{REFERENCES}

Abarajith, H.S., and Dhir, V.K., 2002, "A numerical study of the effect of contact angle on the dynamics of a single bubble during pool boiling," ASME International Mechanical Engineering Congress and Exposition, New Orleans, Louisiana, 7, 467-475. https://doi.org/10.1115/IMECE2002-33876

Abo-Zahhad, E.M., Ookawara, S., Radwan, A., Memon, S., Yang, Y., EI-Kady, M.F., and EI-Shazly, A.H., 2021, "Flow boiling in a fourcompartment heat sink for high-heat flux cooling: A parametric study," Energy Conversion and Management, 230, 113778. https://doi.org/10.1016/j.enconman.2020.113778

Ahmadi, V.E., Aboubakri, A., Sadaghiani, A.K., Sefiane, K., and Koșar, A., 2020, "Effect of functional surfaces with gradient mixed wettability on flow boiling in a high aspect ratio microchannel," Fluids, 5(4), 239. https://doi.org/10.3390/fluids5040239

Ahn, H.S., Kang, S.H., Lee, C., Kim, J., and Kim, M.H., 2012, "The effect of liquid spreading due to micro-structures of flow boiling critical heat flux," International Journal of Multiphase Flow, 43, 1-12. https://doi.org/10.1016/j.ijmultiphaseflow.2012.02.003 
Allred, T.P., Weibel, J.A., and Garimella, S.V., 2021, "The role of dynamic wetting behavior during bubble growth and departure from a solid surface," International Journal of Heat and Mass Transfer, 172, 121167.

https://doi.org/10.1016/j.ijheatmasstransfer.2021.121167

Aravinthan, M., Sarkar, S., Dhar, P., Das, S.K., and Balakrishnam, A.R., 2018, "Flow boiling heat transfer characteristics in minitubes with and without hydrophobicity coating," Heat Transfer Engineering, 41(3), 288-301.

https://doi.org/10.1080/01457632.2018.1528066

Basu, N., Warrier, G.R., and Dhir, V.K., 2002, "Onset of nucleate boiling and active nucleation site density during subcooled flow boiling," Journal of Heat Transfer, 124(4), 717-728.

https://doi.org/10.1115/1.1471522

Bertossi, R., Caney, N., Gruss, J.A., and Poncelet, O., 2015, "Pool boiling enhancement using switchable polymers coating," Applied Thermal Engineering, 77, 121-126.

https://doi.org/10.1016/j.applthermaleng.2014.11.061

Bottini, J.L., Kumar, V., Hammouti, S., Ruzic, D., and Brooks, C.S., 2018, "Influence of wettability due to laser-texturing on critical heat flux in vertical flow boiling," International Journal of Heat and Mass Transfer, 127, 806-817.

https://doi.org/10.1016/j.ijheatmasstransfer.2018.06.113

Carey, V.P., 1992, "Liquid-vapor phase-change phenomena," Hemisphere, Washington.

Chen, Y.J., Yu, B., Zou, Y., Chen, B.N., and Tao, W.Q., 2020, "Molecular dynamics studies of bubble nucleation on a grooved substrate," International Journal of Heat and Mass Transfer, 158, 119850.

https://doi.org/10.1016/j.ijheatmasstransfer.2020.11985

Cheng, H.C., Jiang, Z.X., Chang, T.L., and Chen, P.H., 2021, "Effects of difference in wettability level of biphilic patterns on copper tubes in pool boiling heat transfer," Experimental Thermal and Fluid Science, 120, 110241.

https://doi.org/10.1016/j.expthermflusci.2020.110241

Choi, C., Shin, J.S., Yu, D.I., and Kim, M.H., 2011, "Flow boiling behaviors in hydrophilic and hydrophobic microchannels," Experimental thermal and fluid science, 35(5), 816-824.

https://doi.org/10.1016/j.expthermflusci.2010.07.003

Cole, R., 1974, "Boiling nucleation," Advances in Heat Transfer, 10, 85 166.

https://doi.org/10.1016/S0065-2717(08)70110-2

Dhir, V.K., 1998, "Boiling heat transfer," Annual Review of Fluid Mechanics, 30, 365-401.

https://doi.org/10.1146/annurev.fluid.30.1.365

Dong, L., Cheng, P., and Quan, X.J., 2012, "Availability analyses for heterogeneous nucleation under steady heating in pool boiling," International Communications in Heat and Mass Transfer, 39(6), 776780.

https://doi.org/10.1016/j.icheatmasstransfer.2012.05.004

Fan, S.M., Jiao, L.S., Wang, K., and Duan, F., 2020, "Pool boiling heat transfer of saturated water on rough surfaces with the effect of roughening techniques," International Journal of Heat and Mass Transfer, 159, 120054.

https://doi.org/10.1016/j.ijheatmasstransfer.2020.120054

Fedoseev, A.V., Surtaev, A.S., Moiseev, M.I., and Ostapchenko, A.E., 2020, "Lattice Boltzmann simulation of bubble evolution at boiling on surfaces with different wettability," Journal of Physics Conference Series, 1677, 012085. https://doi.org/10.1088/1742-6596/1677/1/012085

Ferjančič, K., Može, M., Križan, P., Bobič, M., and Golobič, I., 2020, "Subcooled critical heat flux on laser-textured stainless-steel ribbon heaters in pool boiling of Fc-72," International Journal of Heat and Mass Transfer, 159, 120090.

https://doi.org/10.1016/j.ijheatmasstransfer.2020.120090

Forrest, E., Williamson, E., Buongiorno, J., Hu, L.W., Rubner, M., and Cohen, R., 2010, "Augmentation of nucleate boiling heat transfer and critical heat flux using nanoparticle thin-film coatings," International Journal of Heat and Mass Transfer, 53(1-3), 58-67. https://doi.org/10.1016/j.ijheatmasstransfer.2009.10.008

Fritz, W., 1935, "Berechnung des maximalvolumens von dampfblasen," Phys. Z. 36, 379-384.

Guo, H., Ji, X.B., and Xu, J.L., 2020, "Research and development of loop heat pipe - a review," Frontiers in Heat and Mass Transfer, 14, 14. https://doi.org/10.5098/hmt.14.14

Gupta, S.K., and Misra, R.D., 2018, “An experimental investigation on flow boiling heat transfer enhancement using $\mathrm{Cu}-\mathrm{TiO}_{2}$ nanocomposite coating on copper substrate," Experimental Thermal and Fluid Science, 98, 406-419.

https://doi.org/10.1016/j.expthermflusci.2018.06.012

Gupta, S.K., and Misra, R.D., 2020, "Enhancement of flow boiling heat transfer performance using single-step electrodeposited $\mathrm{Cu}-\mathrm{Al}_{2} \mathrm{O}_{3}$ nanocomposite coating on copper substrate," Iranian Journal of Science and Technology-Transactions of Mechanical Engineering, 44(2), 481496.

https://doi.org/10.1007/s40997-018-0274-6

Gupta, S.K., and Misra, R.D., 2021, "Flow boiling performance analysis of copper-titanium oxide micro-/nanostructured surfaces developed by single-step forced convection electrodeposition technique," Arabian Journal for Science and Engineering. https://doi.org/10.1007/s13369-021-05850-x

Gupta, S.K., and Misra, R.D., 2021, "Flow boiling heat transfer performance of copper-alumina micro-nanostructured surfaces developed by forced convection electrodeposition technique," Chemical Engineering and Processing - Process Intensification, 164, 108408. https://doi.org/10.1016/j.cep.2021.108408

Haramura, Y., and Katto, Y., 1983, "A new hydrodynamic model of critical heat flux, applicable widely to both pool and forced convection boiling on submerged bodies in saturated liquids," International Journal of Heat and Mass Transfer, 26(3), 389-399. https://doi.org/10.1016/0017-9310(83)90043-1

He, M.H., Liao, D., and Qiu, H.H., 2017, "Multicomponent droplet evaporation on chemical micro-patterned surfaces," Scientific Reports, $\mathbf{7}$, 41897.

https://doi.org/10.1038/srep41897

Hong, S.H., Zhang, B.H., Dang, C.B., and Hihara, E.J., 2020, "Development of two-phase flow microchannel heat sink applied to solar-tracking high-concentration photovoltaic thermal hybrid system," Energy, 212, 118739.

https://doi.org/10.1016/j.energy.2020.118739

Hsu, C.C., and Chen, P.H., 2012, "Surface wettability effects on critical heat flux of boiling heat transfer using nanoparticle coatings," International Journal of Heat and Mass Transfer, 55(13-14), 3713-3719. https://doi.org/10.1016/j.ijheatmasstransfer.2012.03.003

Hsu, W.T., Lee, D., Lee, N., Yun, M., and Cho, H.H., 2021, "Enhancement of flow boiling heat transfer using heterogeneous wettability patterned surfaces with varying inter-spacing," International Journal of Heat and Mass Transfer, 164, 120596. 


\section{https://doi.org/10.1016/j.ijheatmasstransfer.2020.120596}

Hsu, Y.Y., 1962, "On the size range of active nucleation cavities on a heating surface," Journal of Heat Transfer, 84(3), 207-213. https://doi.org/10.1115/1.3684339

Jo, H., Ahn, H.S., Kang, S., and Kim, M.H., 2011, “A study of nucleate boiling heat transfer on hydrophilic, hydrophobic and heterogeneous wetting surfaces," International Journal of Heat and Mass Transfer, 54(25-26), 5643-5652.

https://doi.org/10.1016/j.ijheatmasstransfer.2011.06.001

Jo, H., Kim, S., Park, H.S., and Kim, M.H., 2014, "Critical heat flux and nucleate boiling on several heterogeneous wetting surfaces: Controlled hydrophobic patterns on a hydrophilic substrate," International Journal of Multiphase Flow, 62, 101-109.

https://doi.org/10.1016/j.ijmultiphaseflow.2014.02.006

Jo, H., Kaviany, M., Kim, S.H., and Kim, M.H., 2014, "Heterogeneous bubble nucleation on ideally-smooth horizontal heated surface," International Journal of Heat and Mass Transfer, 71, 149-157. https://doi.org/10.1016/j.ijheatmasstransfer.2013.12.040

Jo, H.J., Kim, S.H., Kim, H., Kim, J., and Kim, M.H., 2012, "Nucleate boiling performance on nano/microstructures with different wetting surfaces," Nanoscale Research Letters, 7(1), 242.

https://doi.org/10.1186/1556-276X-7-242

Jo, H.J., Park, H.S., and Kim, M.H., 2016, "Single bubble dynamics on hydrophobic-hydrophilic mixed surfaces," International Journal of Heat and Mass Transfer, 93, 554-565.

https://doi.org/10.1016/j.ijheatmasstransfer.2015.09.031

Kandlikar, S.G., 2002, "Fundamental issues related to flow boiling in minichannels and microchannels," Experimental Thermal and Fluid Science, 26(2-4), 389-407.

https://doi.org/10.1016/S0894-1777(02)00150-4

Kim, J., and Lee, J.S., 2019, "Numerical study on the effects of inertia and wettability on subcooled flow boiling in microchannels," Applied Thermal Engineering, 152, 175-183.

https://doi.org/10.1016/j.applthermaleng.2019.02.064

Kim, J., Cho, J.Y., and Lee, J.S., 2020, "Flow boiling enhancement by bubble mobility on heterogeneous wetting surface in microchannel," International Journal of Heat and Mass Transfer, 153, 119631. https://doi.org/10.1016/j.ijheatmasstransfer.2020.119631

Kim, J.M., Kang, S.H., Yu, D.I., Park, H.S., Moriyama, K., and Kim, M.H., 2017, "Smart surface in flow boiling: Spontaneous change of wettability," International Journal of Heat and Mass Transfer, 105, 147156.

https://doi.org/10.1016/j.ijheatmasstransfer.2016.09.047

Kim, J.M., Yu, D.I., Park, H.S., Moriyama, K., and Kim, M.H. 2017, "Smart surface in pool boiling: Thermally-induced wetting transition," International Journal of Heat and Mass Transfer, 109, 231-241. https://doi.org/10.1016/j.ijheatmasstransfer.2017.02.009

Kim, J.M., Kim, T., Yu, D.I., Kim, M.H., Moriyama, K., and Park, H.S. 2017, "Time effect on wetting transition of smart surface and prediction of the wetting transition for critical heat flux in pool boiling," International Journal of Heat and Mass Transfer, 114, 735-742. https://doi.org/10.1016/j.ijheatmasstransfer.2017.06.114

Kim, S.J., Bang, I.C., Buongiorno, J., and Hu, L.W., 2006, "Effects of nanoparticle deposition on surface wettability influencing boiling heat transfer in nanofluids," Applied Physics Letters, 89(15), 153107.

https://doi.org/10.1063/1.2360892

Kim, S.J., Bang, I.C., Buongiorno, J., and Hu, L.W., 2007. "Surface wettability change during pool boiling of nanofluids and its effect on critical heat flux," International Journal of Heat and Mass Transfer, 50(19-20), 4105-4116.

https://doi.org/10.1016/j.ijheatmasstransfer.2007.02.002

Kousalya, A.S., Singh, K.P., and Fisher, T.S., 2015, "Heterogeneous wetting surfaces with graphitic petal-decorated carbon nanotubes for enhanced flow boiling," International Journal of Heat and Mass Transfer, 87, 380-389.

https://doi.org/10.1016/j.ijheatmasstransfer.2015.04.029

Lavino, A.D., Smith, E., Magnini, M., and Matar. O.K., 2021, "Surface topography effects on pool boiling via non-equilibrium molecular dynamics simulations," Langmuir, 37(18), 5731-5744.

https://doi.org/10.1021/acs.langmuir.1c00779

Li, D., Wu, G.S., Wang, W., Wang, Y.D., Liu, D., Zhang, D.C., Chen, Y.F., Peterson, G.P., and Yang, R.G., 2012, "Enhancing flow boiling heat transfer in microchannels for thermal management with monolithically-integrated silicon nanowires," Nano Letters, 12(7), 3385 3390.

https://doi.org/10.1021/nl300049f

Li, Q., Kang, Q.J., Francois, M.M., He, Y.L., and Luo, K.H., 2015, "Lattice Boltzmann modeling of boiling heat transfer: The Boiling curve and the effects of wettability," International Journal of Heat and Mass Transfer, 85, 787-796.

https://doi.org/10.1016/j.ijheatmasstransfer.2015.01.136

Li, Q., Yu, Y., Zhou, P., and Yan, H.J., 2018, "Enhancement of boiling heat transfer using hydrophilic-hydrophobic mixed surfaces: A lattice Boltzmann Study," Applied Thermal Engineering, 132, 490-499.

https://doi.org/10.1016/j.applthermaleng.2017.12.105

Li, W.X., Li, Q., Yu, Y., and Wen, Z.X., 2020, “Enhancement of nucleate boiling by combining the effects of surface structure and mixed wettability: A lattice Boltzmann study," Applied Thermal Engineering, 180, 115849.

https://doi.org/10.1016/j.applthermaleng.2020.115849

Li, Y.Y., Li, Y.T., Jiao, W., Chen, X.Q., and Lu, G., 2021, “Manipulating the heat transfer of pool boiling by tuning the bubble dynamics with mixed wettability surfaces," International Journal of Heat and Mass Transfer, 170, 120996.

https://doi.org/10.1016/j.ijheatmasstransfer.2021.120996

Lian, W.L., Sun, Z.J., Han, T.Y., and Xuan, Y.M., 2020, "Experiment study on the boiling heat transfer of liquid film in a rotating pipe," Frontiers in Heat and Mass Transfer, 14, 10.

https://doi.org/10.5098/hmt.14.10

Lin, Y., Luo, Y., Li, J., and Li. W., 2021, "Heat transfer, pressure drop and flow patterns of flow boiling on heterogeneous wetting surface in a vertical narrow microchannel," International Journal of Heat and Mass Transfer, 172, 121158.

https://doi.org/10.1016/j.ijheatmasstransfer.2021.121158

Li, Y., Zhou, W.J., Zhang, Y.H., Qi, B.J., and Wei, J.J., 2020, “A molecular dynamics study of surface wettability effects on heterogeneous bubble nucleation," International Communications in Heat and Mass Transfer, 119, 104991.

https://doi.org/10.1016/j.icheatmasstransfer.2020.10499

Lin, Y.H., Li, J.Y., Sun, J., Li, W., and Cao, Y.L., 2021, “'Onset of boiling, heat transfer, and flow patterns of flow boiling on the superhydrophobic porous copper surface in a microchannel," Journal of Heat TransferTransactions of the ASME, 143(8), 081602.

https://doi.org/10.1115/1.4051324

Liu, D., Lee, P.S., and Garimella, S.V., 2005, "Prediction of the onset of nucleate boiling in microchannel flow," International Journal of Heat and Mass Transfer, 48(25-26), 5134-5149. 


\section{https://doi.org/10.1016/j.ijheatmasstransfer.2005.07.021}

Liu, T.Y., Li, P.L., Liu, C.W., and Gau, C., 2011, "Boiling flow characteristics in microchannels with very hydrophobic surface to superhydrophilic surface," International Journal of Heat and Mass Transfer, 54(1-3), 126-134.

https://doi.org/10.1016/j.ijheatmasstransfer.2010.09.060

Malenkov, I.G., 1971, "Detachment frequency as a function of size for vapor bubbles," Journal of engineering physics, 20, 704-708. https://doi.org/10.1007/BF01122590

Meng, X.Q., Zhao, D.X., Zhang, J.Y., Shen, D.Z., Lu, Y.M., Dong, L., Xiao, Z.Y., Liu, Y.C., and Fan, X.W., 2005, "Wettability conversion on $\mathrm{ZnO}$ nanowire arrays surface modified by oxygen plasma treatment and annealing," Chemical Physics Letters, 413(4-6), 450-453.

https://doi.org/10.1016/j.cplett.2005.08.039

Mer, V. K. L., 1952, "Nucleation in Phase Transitions," Industrial and Engineering Chemistry, 44(6), 1270-1277.

https://doi.org/10.1021/ie50510a027

Mikic, B.B., and Rohsenow, W.M., 1969, "A new correlation of poolboiling data including the effect of heating surface characteristics," Journal of Heat Transfer, 91(2), 245-250.

https://doi.org/10.1115/1.3580136

Mohammadi, N., Fadda, D., Choi, C.K., Lee, J., and You, S.M., 2018, "Effects of surface wettability on pool boiling of water using superpolished silicon surfaces," International Journal of Heat and Mass Transfer, 127, 1128-1137.

https://doi.org/10.1016/j.ijheatmasstransfer.2018.07.122

Morshed, A.K.M.M., Paul, T.C., and Khan, J., 2013, "Effect of $\mathrm{Cu}-$ $\mathrm{Al}_{2} \mathrm{O}_{3}$ nanocomposite coating on flow boiling performance of a microchannel," Applied Thermal Engineering, 51(1-2), 1135-1143.

https://doi.org/10.1016/j.applthermaleng.2012.09.047

Morshed, A.K.M.M., Paul, T.C., and Khan, J.A., 2013, "Effect of $\mathrm{Al}_{2} \mathrm{O}_{3}$ nanoparticle deposition on flow boiling performance of water in a microchannel," Experimental Thermal and Fluid Science, 47, 6-13. https://doi.org/10.1016/j.expthermflusci.2012.11.015

Mukherjee, A., Kandlikar, S.G., and Edel, Z.J., 2011, "Numerical study of bubble growth and wall heat transfer during flow boiling in a microchannel," International Journal of Heat and Mass Transfer, 54(1516), 3702-3718

https://doi.org/10.1016/i.ijheatmasstransfer.2011.01.030

Myers, J.G., Yerramilli, V.K., Hussey, S.W., Yee, G.F., and Kim, J., 2005, "Time and space resolved wall temperature and heat flux measurements during nucleate boiling with constant heat flux boundary conditions," International Journal of Heat and Mass Transfer, 48(12), 2429-2442. https://doi.org/10.1016/j.ijheatmasstransfer.2004.12.050

Nam, Y., Aktinol, E., Dhir, V.K., and Ju, Y.S., 2011, "Single bubble dynamics on a superhydrophilic surface with artificial nucleation sites," International Journal of Heat and Mass Transfer, 54(7-8), 1572-1577. https://doi.org/10.1016/j.ijheatmasstransfer.2010.11.031

Nam, Y., Wu, J.F., Warrier, G., and Ju, Y.S., 2009, "Experimental and numerical study of single bubble dynamics on a hydrophobic surface," Journal of Heat Transfer, 131(12), 121004.

https://doi.org/10.1115/1.3216038

Nedaei, M., Armagan, E., Sezen, M., Ince, G.O., and Kosar, A., 2016, "Enhancemet of flow boiling heat transfer in pHEMA/pPFDA coated microtubes with longitudinal variations in wettability," AIP Advances, 6(3), 035212.

https://doi.org/10.1063/1.4944581
Nedaei, M., Motezakker, A.R., Zeybek, M.C., Sezen, M., Ince, G.O., and Kosar, A., 2017, "Subcooled flow boiling heat transfer enhancement using polyperfluorodecylacrylate (Ppfda) coated microtubes with different coating thicknesses," Experimental Thermal and Fluid Science, 86, $130-140$.

https://doi.org/10.1016/j.expthermflusci.2017.04.008

Nie, D.M., and Guan, G., 2021, "Study on boiling heat transfer in a shear flow through the lattice Boltzmann method," Physics of Fluids, 33(4), 013314.

https://doi.org/10.1063/5.0047580

Phan, H.T., Caney, N., Marty, P., Colasson, S., and Gavillet, J., 2009 "Surface wettability control by nanocoating: The effects on pool boiling heat transfer and nucleation mechanism," International Journal of Heat and Mass Transfer, 52(23-24), 5459-5471.

https://doi.org/10.1016/j.ijheatmasstransfer.2009.06.032

Phan, H.T., Caney, N., Marty, P., Colasson, S., and Gavillet, J., 2011, "Flow boiling of water on titanium and diamond-like carbon coated surfaces in a microchannel," Frontiers in Heat and Mass Transfer, 2(1), 3002.

https://doi.org/10.5098/hmt.v2.1.3002

Phan, H.T., Caney, N., Marty, P., Colasson, S., and Gavillet, J., 2011, "Flow boiling of water in a minichannel: The effects of surface wettability on two-phase pressure drop," Applied Thermal Engineering, 31(11-12), 1894-1905. https://doi.org/10.1016/j.applthermaleng.2011.02.036

Phan, H.T., Caney, N., Marty, P., Colasson, S., and Gavillet, J., 2012, "Flow boiling of water on nanocoated surfaces in a microchannel," Journal of Heat Transfer, 134(2), 121-127.

https://doi.org/10.1115/1.4004935

Pontes, P., Cautela, R., Teodori, E., Motia, A., Liu, Y., Moreira, A.L.N., Nikulin, A., and del Barrio, E.P., 2020, "Effect of pattern geometry on bubble dynamics and heat transfer on biphilic surfaces," Experimental Thermal and Fluid Science, 115, 110088. https://doi.org/10.1016/j.expthermflusci.2020.110088

Pontes, P., Cautela, R., Teodori, E., Moita, A.S., and Moreira, A.L.N. 2020, "Experimental description of bubble dynamics and heat transfer processes occurring on the pool boiling of water on biphilic surfaces," Applied Thermal Engineering, 178, 115507. https://doi.org/10.1016/j.applthermaleng.2020.115507

Qin, J., Xu, Z.Y., and Xu, Z.G., 2020, "Pore-scale investigation on flow boiling heat transfer mechanisms in gradient open-cell metal foams by LBM," International Communications in Heat and Mass Transfer, 119 , 104974 https://doi.org/10.1016/j.icheatmasstransfer.2020.104974

Quan, X., Chen, G., and Cheng, P., 2011, "A thermodynamic analysis for heterogeneous boiling nucleation on a superheated wall," International Journal of Heat and Mass Transfer, 54(21-22), 4762-4769. https://doi.org/10.1016/j.ijheatmasstransfer.2011.05.026

Ruiz, M., Kunkle, C., Padilla, J., and Carey, V.P., 2017, "Boiling heat transfer performance in a spiraling radial inflow microchannel cold plate," Heat Transfer Engineering, 38(14-15), 1247-1259. https://doi.org/10.1080/01457632.2016.1242954

Sadaghiani, A.K., Altay, R., Noh, H., Kwak, H.J., Şendur, K., Misırlığlu, B., Park, H.S., and Koşar, A., 2019, "Effects of bubble coalescence on pool boiling heat transfer and critical heat flux - A parametric study based on artificial cavity geometry and surface wettability," International Journal of Heat and Mass Transfer, 147, 118952. https://doi.org/10.1016/j.ijheatmasstransfer.2019.11895

Sadasivan, P., Chappidi, P.R., Unal, C., and Nelson, R.A., 1992, 
"Possible mechanisms of macrolayer formation," International Communications in Heat and Mass Transfer, 19(6), 801-815.

https://doi.org/10.1016/0735-1933(92)90016-B

Sarker, D., Ding, W., Schneider, C., and Hampel, U., 2019, "Single bubble dynamics during nucleate flow boiling on a vertical heater: Experimental and theoretical analysis of the effect of surface wettability, roughness and bulk liquid velocity," International Journal of Heat and Mass Transfer, 142, 118481

https://doi.org/10.1016/j.ijheatmasstransfer.2019.118481

Sarwar, M.S., Jeong, Y.H., and Chang, S.H., 2007, "Subcooled flow boiling CHF enhancement with porous surface coatings," International Journal of Heat and Mass Transfer, 50(17-18), 3649-3657. https://doi.org/10.1016/i.ijheatmasstransfer.2006.09.011

Shi, J., Jia, X., Feng, D.Y., Chen, Z.Q., and Dang, C.B., 2020, "Wettability effect on pool boiling heat transfer using a multiscale copper foam surface," International Journal of Heat and Mass Transfer, 146, 118726.

https://doi.org/10.1016/j.ijheatmasstransfer.2019.118726

Sommers, A.D., and Yerkes, K.L., 2013, "Using micro-structural surface features to enhance the convective flow boiling heat transfer of R-134a on aluminum," International Journal of Heat and Mass Transfer, 64, 1053-1063.

https://doi.org/10.1016/j.ijheatmasstransfer.2013.05.053

Suhas, B.G., Sathyabhama, A., Veerabhadrappa, K., Kumar, R.S., and Kumar, U.K., 2019, "Wall heat flux partitioning analysis for subcooled flow boiling of water-ethanol mixture in conventional channel," Frontiers in Heat and Mass Transfer, 13, 16. https://doi.org/10.5098/hmt.13.16

Sujith Kumar, C.S., Suresh, S., Aneesh, C.R., Santhosh Kumar, M.C., Praveen, A.S., and Raji, K., 2015, "Flow boiling heat transfer enhancement on copper surface using $\mathrm{Fe}$ doped $\mathrm{Al}_{2} \mathrm{O}_{3}-\mathrm{TiO}_{2}$ composite coatings," Applied Surface Science, 334, 102-109.

https://doi.org/10.1016/j.apsusc.2014.08.076

Sujith Kumar, C.S., Suresh, S., Praveen, A.S., Santhosh Kumar, M.C., and Gopi, V., 2016, "Effect of surfactant addition on hydrophilicity of $\mathrm{Zno}-\mathrm{Al}_{2} \mathrm{O}_{3}$ composite and enhancement of flow boiling heat transfer," Experimental Thermal and Fluid Science, 70, 325-334.

https://doi.org/10.1016/j.expthermflusci.2015.09.014

Sun, R., Nakajima, A., Fujishima, A., Watanabe, T., and Hashimoto, K., 2001, "Photoinduced surface wettability conversion of $\mathrm{ZnO}$ and $\mathrm{TiO}_{2}$ thin films," Journal of Physical Chemistry B, 105, 1984-1990. https://doi.org/10.1021/JP002525J

Takata, Y., Hidaka, S., Cao, J.M., Nakamura, T., Yamamoto, H., Masuda, M., and Ito, T., 2005, "Effect of surface wettability on boiling and evaporation," Energy, 30(2-4), 209-220

https://doi.org/10.1016/j.energy.2004.05.004

Takata, Y., Hidaka, S., and Uraguchi, T., 2006, "Boiling feature on a super water-repellent surface," Heat Transfer Engineering, 27(8), 25-30. https://doi.org/10.1080/01457630600793962

Tang, J.B., Lambie, S., Meftahi, N., Christofferson, A.J., Yang, J., Ghasemian, M.B., Han, J.L., Alioux, F.M., Rahim, M.A., Mayyas, M., Daeneke, T., Mcconville, C.F., Steenbergen, K.G., Kaner, R.B., Russo, S.P., Gaston, N., and Kalantar-Zadeh, K., 2021, "Unique surface patterns emerging during solidification of liquid metal alloys," Nature Nanotechnology.

https://doi.org/10.1038/s41565-020-00835-7

Theofanous, T.G., Dinh, T.N., Tu, J.P., and Dinh, A.T., 2002, “The boiling crisis phenomenon: Part II: dryout dynamics and burnout," Experimental Thermal and Fluid Science, 26(6-7), 793-810.

\section{https://doi.org/10.1016/S0894-1777(02)00193-0}

Theofanous, T.G., and Dinh, T.N., 2006, "High heat flux boiling and burnout as microphysical phenomena: mounting evidence and opportunities," Multiphase Science and Technology, 18(3), 251-276. https://doi.org/10.1615/MultScienTechn.v18.i3.30

Wang, B., He, M.H., Wang, H.Z., and Qiu, H.H., 2017, "Flow boiling heat transfer in wettability patterned microchannels," 16th IEEE Intersociety Conference on Thermal and Thermomechanical Phenomena in Electronic Systems (Itherm), Orlando, 759-766. https://doi.org/10.1109/ITHERM.2017.7992562

Wang, H.Z., Yang, Y.C., He, M.H., and Qiu, H.H., 2019, "Subcooled flow boiling heat transfer in a microchannel with chemically patterned surfaces," International Journal of Heat and Mass Transfer, 140, 587 597.

\section{https://doi.org/10.1016/j.ijheatmasstransfer.2019.06.027}

Wenzel, R.N., 1936, "Resistance of solid surface to wetting by water," Industrial and Engineering Chemistry, 28(8), 988-994. https://doi.org/10.1021/ie50320a024

Wi, Y.J., Kim, J.H., Lee, J.S., and Lee, J.S., 2018, “Optimal patterned wettability for microchannel flow boiling using the Lattice Boltzmann Method," Coatings, 8(8), 288.

https://doi.org/10.3390/coatings 8080288

Wu, N.N., Zeng, L.C., Fu, T., Wang, Z.H., and Lu, C. 2020, "Molecular dynamics study of rapid boiling of thin liquid water film on smooth copper surface under different wettability conditions. International Journal of Heat and Mass Transfer, 147, 118905. https://doi.org/10.1016/i.ijheatmasstransfer.2019.118905

Yang, F.H., Dai, X.M., Peles, Y., Cheng, P., and Li, C., 2013, "Can multiple flow boiling regimes be reduced into a single one in microchannels?" Applied Physics Letters, 103, 043122.

https://doi.org/10.1063/1.4816594

Yang, F.H., Dai, X.M., Peles, Y., Cheng, P., Khan, J., and Li, C., 2014, "Flow boiling phenomena in a single annular flow regime in microchannels (I): Characterization of flow boiling heat transfer," International Journal of Heat and Mass Transfer, 68, 703-715. https://doi.org/10.1016/j.ijheatmasstransfer.2013.09.058

Yang, F.H., Dai, X.M., Peles, Y., Cheng, P., Khan, J., and Li, C., 2014, "Flow boiling phenomena in a single annular flow regime in microchannels (II): Reduced pressure drop and enhanced critical heat flux," International Journal of Heat and Mass Transfer, 68, 716-724. https://doi.org/10.1016/j.ijheatmasstransfer.2013.09.060

Yim, K., Lee, J., Naccarato, B., and Kim, K.J., 2019, “Surface wettability effect on nucleate pool boiling heat transfer with titanium oxide $\left(\mathrm{TiO}_{2}\right)$ coated heating surface," International Journal of Heat and Mass Transfer, 133, 352-358.

https://doi.org/10.1016/j.ijheatmasstransfer.2018.12.075

Yu, Y., Wen, Z.X., Li, Q., Zhou, P., and Yan, H.J., 2018, "Boiling heat transfer on hydrophilic-hydrophobic mixed surfaces: A 3D lattice Boltzmann study," Applied Thermal Engineering, 142, 846-854. https://doi.org/10.1016/j.applthermaleng.2018.07.059

Yuan, J.J., Weng, Z.H., and Shan, Y.G., 2021, "Modelling of double bubbles coalescence behavior on different wettability walls using LBM method," International Journal of Thermal Sciences, 168, 107037. https://doi.org/10.1016/j.ijthermalsci.2021.107037

Zhang, B.J., Ganguly, R., Kim, K.J., and Lee, C.Y., 2017, "Control of pool boiling heat transfer through photo-induced wettability change of titania nanotube arrayed surface," International Communications in Heat and Mass Transfer, 81, 124-130.

https://doi.org/10.1016/i.icheatmasstransfer.2016.12.007 
Zhang, L., Wang, T., Kim, S., and Jiang, Y.Y., 2020, "The effects of wall superheat and surface wettability on nucleation site interactions during boiling," International Journal of Heat and Mass Transfer, 146, 118820. https://doi.org/10.1016/j.ijheatmasstransfer.2019.118820

Zhang, S.W., Jiang, X.C., Li, Y.J., Chen, G., Sun, Y.L., Tang, Y., and Pan, C., 2020, "Extraordinary boiling enhancement through microchimney effects in gradient porous micromeshes for high-power applications," Energy Conversion and Management, 209, 112665. https://doi.org/10.1016/j.enconman.2020.112665

Zhao, H., Zhou, L.P., and Du, X.Z., 2021, "Bubble nucleation on grooved surfaces with hybrid wettability: molecular dynamics study under a transient temperature boundary condition," International Journal of Heat and Mass Transfer, 166, 120752.

https://doi.org/10.1016/j.ijheatmasstransfer.2020.120752
Zheng, J.Y., Bao, S.H., Guo, Y., and Jin, P., 2014, "Natural hydrophobicity and reversible wettability conversion of flat anatase $\mathrm{TiO}_{2}$ thin film," ACS Applied Materials and Interfaces, 6(3), 1351-1355. https://doi.org/10.1021/am404470e

Zuber, N., 1963, "Nucleate boiling. The region of isolated bubbles and the similarity with natural convection," International Journal of Heat and Mass Transfer, 6, 53-60. https://doi.org/10.1016/0017-9310(63)90029-2

Zupančič, M., Steinbücher, M., Gregorčič, P., and Golobič, I., 2015, "Enhanced pool-boiling heat transfer on laser-made hydrophobic/superhydrophilic polydimethylsiloxane-silica patterned surfaces," Applied Thermal Engineering, 91, 288-297. https://doi.org/10.1016/j.applthermaleng.2015.08.026 